\title{
Overzicht onderwijs-arbeidsmarkt Euregio Maas - Rijn
}

Citation for published version (APA):

de Grip, A. (1996). Overzicht onderwijs-arbeidsmarkt Euregio Maas - Rijn. Researchcentrum voor Onderwijs en Arbeidsmarkt, Faculteit der Economische Wetenschappen. ROA Reports No. 13 https://doi.org/10.26481/umarep.1996013

Document status and date:

Published: 01/01/1996

DOI:

10.26481/umarep.1996013

Document Version:

Publisher's PDF, also known as Version of record

\section{Please check the document version of this publication:}

- A submitted manuscript is the version of the article upon submission and before peer-review. There can be important differences between the submitted version and the official published version of record.

People interested in the research are advised to contact the author for the final version of the publication, or visit the DOI to the publisher's website.

- The final author version and the galley proof are versions of the publication after peer review.

- The final published version features the final layout of the paper including the volume, issue and page numbers.

Link to publication

\footnotetext{
General rights rights.

- You may freely distribute the URL identifying the publication in the public portal. please follow below link for the End User Agreement:

www.umlib.nl/taverne-license

Take down policy

If you believe that this document breaches copyright please contact us at:

repository@maastrichtuniversity.nl

providing details and we will investigate your claim.
}

Copyright and moral rights for the publications made accessible in the public portal are retained by the authors and/or other copyright owners and it is a condition of accessing publications that users recognise and abide by the legal requirements associated with these

- Users may download and print one copy of any publication from the public portal for the purpose of private study or research.

- You may not further distribute the material or use it for any profit-making activity or commercial gain

If the publication is distributed under the terms of Article $25 \mathrm{fa}$ of the Dutch Copyright Act, indicated by the "Taverne" license above, 


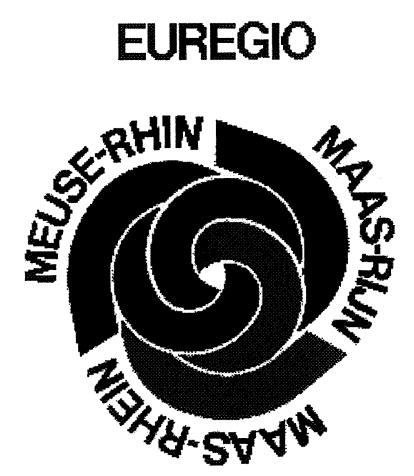

Overzicht onderwijs-arbeidsmarkt Euregio Maas - Rijn

\author{
Plan d'ensemble enseignement-marché \\ du travail Eurégion Meuse-Rhin \\ Übersicht Ausbildung und Arbeitsmarkt \\ in der Euregio Maas-Rhein
}

ROA-R-1996/13

STC-Arbeidsmarktobservatorium, Genk

Arbeitsmarktbeobachtungsstelle Ostbelgien, St. Vith

FOREM, Liège

Landes Arbeitsamt NRW, Düsseldorf

Researchcentrum voor Onderwijs en Arbeidsmarkt, Maastricht

Researchcentrum voor Onderwijs en Arbeidsmarkt

Faculteit der Economische Wetenschappen en Bedrijfskunde

Universiteit Maastricht

Maastricht, december 1996 
ISBN 90-5321-194-2 


\section{Resumé}

\section{Bevolking}

Het totaal aantal inwoners in de Euregio bedroeg op 1 januari 1995 3.751.627. Bij de bevolkingsopbouw in de Euregio valt op dat de "ontgroening" het sterkst is in de Regio Aachen. Het percentage 0-24 jarigen is in deze regio het laagst. De leeftijdsgroep van 45 jaar en ouder is wat oververtegenwoordigd in de Regio Aachen. In Belgisch Limburg daarentegen is deze groep relatief klein.

Het aandeel van allochtonen in de bevolking varieert nogal tussen de verschillende Euregiodelen. Zo is in Zuid-Limburg 5,4\% van de bevolking allochtoon, terwijl het aandeel allochtonen in de Deutschsprachige Gemeinschaft $15,6 \%$ bedraagt. Ook bestaan tussen de steden in de Euregio op dit punt grote verschillen. In Genk is $24,2 \%$ van de bevolking allochtoon; in Sankt Vith bedraagt het percentage allochtonen slechts $3,5 \%$.

Zuid-Limburg is met 822 inwoners per vierkante kilometer het dichtstbevolkste Euregiodeel. In alle andere Euregiodelen is de bevolkingsdichtheid veel lager: de Regio Aachen heeft 349 inwoners per $\mathrm{km}^{2}$, in Belgisch Limburg wonen gemiddeld 319 inwoners per $\mathrm{km}^{2}$, de Province de Liège heeft een bevolkingsdichtheid van 263 per $\mathrm{km}^{2}$ en de Deutschsprachige Gemeinschaft is het dunst bevolkt (81 inwoners per $\left.\mathrm{km}^{2}\right)$.

\section{Potentiële beroepsbevolking (bevolking 15-64 jaar)}

Ondanks de soms beperkte vergelijkbaarheid van de gebruikte databronnen kunnen toch enkele conclusies met betrekking tot de participatiegraad (beroepsbevolking als percentage van de potentiële beroepsbevolking) getrokken worden. In Belgisch Limburg is deze het hoogst (63.1\%), gevolgd door Zuid-Limburg, de Deutschsprachige Gemeinschaft en de Province de Liège (allen rond de 55\%). De Regio Aachen lijkt een lagere participatiegraad te hebben $(44,1 \%)$, maar de gebruikte bron staat een vergelijking met de andere Euregiodelen niet toe. De participatiegraad van de jongeren (bevolking 15-24 jaar) is in Belgisch Limburg hoger dan in Zuid-Limburg. Voor de andere Euregiodelen zijn geen vergelijkbare gegevens met betrekking tot de participatie van jongeren beschikbaar. De participatiegraad van ouderen (bevolking 55-64 jaar) ligt in de Euregiodelen waarvoor gegevens beschikbaar zijn rond de $20 \%$.

De typen werkgelegenheid (vaste dienst, flexibel werk, zelfstandigen e.d.) van de werkzame bevolking zijn, door het gebruik van verschillende bronnen en door nationale definitieverschillen erg moeilijk vergelijkbaar. In de Regio Aachen lijkt het aandeel van ambtenaren en zelfstandigen kleiner te zijn dan in een aantal andere Euregiodelen. Ook de typen werkgelegenheid waarin de jongeren emplooi vinden 
zijn tussen de verschillende Euregiodelen niet vergelijkbaar. In de typen werkgelegenheid van de ouderen lijken er weinig verschillen te zitten tussen de Euregiodelen waarvoor data beschikbaar zijn.

In alle Euregiodelen waar gegevens over voltijd- en deeltijdarbeid naar mannen en vrouwen kunnen worden verbijzonderd, werken vrouwen vaker in deeltijd dan mannen. In Zuid-Limburg is het percentage van de bevolking dat in deeltijd werkzaam is het hoogst $(32,5 \%)$, terwijl in de andere Euregiodelen $10-20 \%$ van de werkzame bevolking in deeltijd werkt.

\section{Macro-economische achtergrond}

In alle Euregiodelen is sprake van een geringe groei van het reële bruto regionale produkt (BRP) in de periode 1985-1992 en een kleine teruggang in 1993. In de groeipercentages van het reële BRP over de periode 1988-1993 zijn er kleine verschillen tussen de Euregiodelen. Het laagste groeipercentage is te vinden in Belgisch Limburg (0,8\%); het hoogste in de Regio Aachen $(2,0 \%)$. Wat de groeipercentages voor 1992-1993 betreft geldt hetzelfde. Ook in deze periode lopen de groeipercentages niet ver uiteen, waarbij het BRP van de Province de Liège het sterkste daalt $(-2,7 \%)$ en het BRP van Belgisch Limburg en Zuid-Limburg de geringste daling vertoont: $-1,5 \%$.

Het sectorale patroon van de economische groei wordt in tabel 1 nader toegelicht.

Tabel 1

Groei van het bruto regionaal produkt per sector, 1988-1993 en 1992-1993, per Euregiodeel

\begin{tabular}{|c|c|c|c|c|c|c|c|c|c|c|}
\hline \multirow[b]{2}{*}{ Sector } & \multicolumn{2}{|c|}{ Zuid-Limburg } & \multicolumn{2}{|c|}{ Prov. de Liège } & \multicolumn{2}{|c|}{ Belgisch Limburg } & \multicolumn{2}{|c|}{ Deutschspr. Gem. } & \multicolumn{2}{|c|}{ Regio Aachen } \\
\hline & 88-93 & $92-93$ & 88-93 & $92-93$ & $88-93$ & $92-93$ & 88-93 & $92-93$ & $88-93$ & $92-93$ \\
\hline $\begin{array}{l}\text { Landbouw/ } \\
\text { bosbouw/visserij }\end{array}$ & + & 0 & + & ++ & ++ & ++ & * & * & $-\infty$ & - - \\
\hline $\begin{array}{l}\text { Industrie en } \\
\text { bouw }\end{array}$ &.-- & - - & + & - & - & - - & $*$ & * & - & -- \\
\hline Diensten & ++ & 0 & + & - & + & 0 & $*$ & * & ++ & ++ \\
\hline Bankdiensten & + & ++ & ++ & ++ & ++ & ++ & $*$ & * & $*$ & * \\
\hline
\end{tabular}

\footnotetext{
- - daling met meer dan $3 \%$ daling tussen 1 en $3 \%$

verandering tussen $-1 \%$ en $+1 \%$

stijging tussen $1 \%$ en $3 \%$

$++\quad$ stijging met meer dan $3 \%$

* Niet beschikbaar
} 


\section{Beroepsbevolking}

In de Euregiodelen Zuid-Limburg, Province de Liège, en Regio Aachen werkt ongeveer $30 \%$ van de werkzame bevolking in de sector industrie en bouwnijverheid. In Belgisch Limburg ligt dit aandeel wat hoger $(36,4 \%)$, terwijl de dienstensector in deze regio kleiner is $(60,4 \%)$. In de Province de Liège werken beduidend meer mensen in de dienstverlening $(69,0 \%)$. Ook in de Deutschprachige Gemeinschaft is het werkgelegenheidsaandeel van deze sector vrij hoog. De sector landbouw en visserij is in alle Euregiodelen klein; het aandeel van de werkzame bevolking in deze sector loopt uiteen van $1,3 \%$ in de Zuid-Limburg tot $3,2 \%$ in Belgisch Limburg.

De sectorale verdeling van de werkgelegenheid wordt enigszins weerspiegeld in de aandelen van bepaalde beroepen in de werkzame bevolking. Zo is in Belgisch Limburg het aandeel van beroepen die veel voorkomen in de industrie hoger dan in de Province de Liège (respectievelijk $32,8 \%$ en $23,3 \%$ ). Daarentegen komen beroepen die vaak te vinden zijn in de dienstensector in de Province de Liège vaker voor dan in Belgisch Limburg.

Werkenden met alleen basisonderwijs komen in Zuid-Limburg vaker voor dan in Belgisch Limburg $(9,9 \%$ vs. $7,0 \%)$. Het aandeel van hoger geschoolden (universitair of niet-universitair hoger onderwijs) in de werkzame beroepsbevolking is in de regio's waarvoor gegevens beschikbaar zijn ongeveer $20 \%$.

In Zuid-Limburg zijn er relatief veel geregistreerde werkloze vrouwen in de beroepscategorieën "handel", "kantoor" en "horeca". Veel geregistreerde werkloze mannen in Zuid-Limburg vallen onder de beroepscategorieën "produktiepersoneel", "metaal" en "transport". Er zijn meer geregistreerde werkloze vrouwen dan mannen in de Province de Liège. In de beroepscategorieën "verkopers", "kantoor", en "diensten" zijn hier veel werkloze vrouwen. De beroepscategorieën "metaal", "bouw" en "vrije beroepen - technici en gelijkgestelden" bevatten een groot deel van de geregistreerde werkloze mannen.

Ook in Belgisch Limburg zijn vrouwen oververtegenwoordigd in de geregistreerde werkloosheid. Werkloze vrouwen vallen vaak onder de beroepscategorie "confectiearbeider", "verkoper" en "huisbewaarder en schoonmaker". De beroepscategorieën "metaalbewerker", "handlanger algemeen" en "bouwarbeider" komen het meest voor bij de geregistreerde mannelijke werklozen. Veel geregistreerde werklozen in de Regio Aachen vallen onder de beroepscategorieën "administratie en kantoor", "algemene dienstverlening" en "verkeer".

Het aandeel van werklozen met alleen basisonderwijs in de Province de Liège en Belgisch Limburg (beiden rond $30 \%$ ) is duidelijk hoger dan in Zuid-Limburg en de Regio Aachen, waar ongeveer $20 \%$ van de geregistreerde werklozen slechts basisonderwijs gevolgd heeft. Het aandeel van werklozen met een universitaire opleiding is in de Regio Aachen het grootst, gevolgd door Zuid-Limburg. Uit de verzamelde 
gegevens blijkt verder dat de werklozen in de twee laatstgenoemde regio's gemiddeld een hoger onderwijsniveau hebben dan in de Euregiodelen Belgisch Limburg en de Province de Liège.

\section{Arbeidsmarkt}

Gemiddeld zijn er in Zuid-Limburg 23 werklozen voor iedere geregistreerde vacature. Probleem-beroepscategorieën (een beroepscategorie met een groot aantal werklozen per vacature) zijn "produktiepersoneel" (124 werklozen per vacature), "magazijnpersoneel" (39 werklozen per vacature) en "onderwijs" (37 werklozen per vacature). In Belgisch Limburg zijn er voor elke vacature gemiddeld 19 werklozen. In de beroepscategorieën "confectiearbeider", "kunstenaar" en "mediapersoneel en andere ambachten" (respectievelijk 280, 160 en 113 werklozen per vacature) doen zich de meeste problemen voor. In de Deutschsprachige Gemeinschaft zijn er gemiddeld 13 geregistreerde werklozen per vacature. In de beroepscategorieën "Dienstverlenende beroepen", "Kantoorberoepen" en "verkoop" lijken zich problemen voor te doen. Gezien de geringe aantallen werklozen en vacatures in deze regio moeten deze cijfers echter met de nodige voorzichtigheid worden geïnterpreteerd. In de Regio Aachen zijn er ook gemiddeld 13 werklozen per vacature. Problematische beroepscategorieën zijn hier: "keramiek- en glasarbeider", "chemie-arbeider" en "monteurs en metaalberoepen".

In figuur 1 worden de bemiddelingsresultaten van de arbeidsbureaus in de verschillende delen van de Euregio met elkaar vergeleken. De vervullingsquote van vacatures is in Zuid-Limburg iets lager dan in Belgisch Limburg. In Zuid-Limburg worden de meeste vacatures vervuld in de industrie $(75,7 \%)$, terwijl in de bedrijfssector landbouw en visserij, waar traditioneel veel met seizoensarbeid gewerkt wordt, de vervullingsquote het laagst is $(61,7 \%)$. In Belgisch Limburg zijn de verschillen tussen de bedrijfssectoren veel groter. Zo is in de sector landbouw, jacht en visserij de vervullingsquote slechts $40,3 \%$. Vervullingsquotes van boven de $90 \%$ komen een aantal keren voor (bijvoorbeeld in de bedrijfssectoren chemie, fabricatie machines en sociale en liefdadige instellingen). In Zuid-Limburg is de vervullingsquote in de beroepscategorie "produktiepersoneel" het hoogst; vacatures uit de beroepscategorie "leidinggevenden" worden het minst goed bemiddeld $(41,8 \%)$. Belgisch Limburg kent een hoge vervullingsquote in de beroepscategorie "paramedicus en verzorging" $(89,7 \%)$; Daarentegen is de vervullingsquote het laagst in de beroepscategorie "landbouwer en visser" (39,9\%). Voor de Province de Liège en de Deutschsprachige Gemeinschaft zijn er alleen totale vervullingsquota beschikbaar van respectievelijk $72,3 \%$ en $73,5 \%$. 


\section{Figuur 1}

Bemiddelingsresultaten per bedrijfstak en beroepscategorie: totale, hoogste en laagste vervullingsquotes

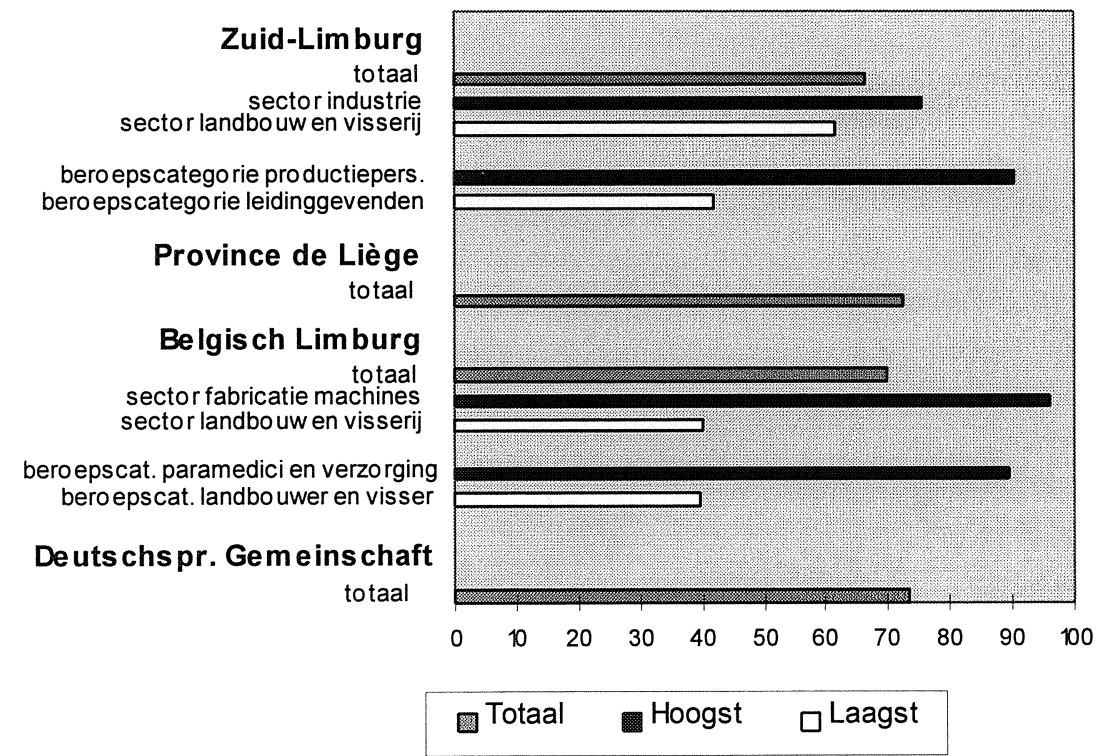





\section{Resumé}

\section{Population}

Le nombre total d'habitants de l'Eurégio étaient de 3.751.627, le 1er janvier 1995. La structure démographique eurégionale montre que c'est dans la Regio Aachen que le vieillissement est le plus notable. C'est dans cette région que les 0-24 ans sont les moins nombreux. Le groupe d'âge des 45 ans et plus, est quelque peu surreprésenté dans la Regio Aachen. Dans le Limbourg belge, au contraire, ce groupe est relativement minime.

La part des allochtones dans la population varie passablement dans les différentes parties de l'Eurégio. Ainsi, dans le Limbourg du Sud, 5,4\% de la population est allochtone, tandis que dans la Deutschsprachige Gemeinschaft la part des allochtones atteint $15,6 \%$. II existe aussi, sur ce point, de grandes différences entre les villes de l'Eurégio. A Genk $24,2 \%$ de la population est allochtone; à Sankt Vith, le pourcentage d'allochtones n'est que de $3,5 \%$.

Avec 822 habitants au kilomètre carré, le Limbourg du Sud est la partie de l'Eurégio la plus densement peuplée. Dans les autres composantes eurégionales la densité de la population est bien inférieure: la Regio Aachen compte 349 habitants au km², le Limbourg belge 319 habitants au $\mathrm{km}^{2}$, la Province de Liège a une densité de population de 263 habitants au $\mathrm{km}^{2}$, et la Deutschsprachige Gemeinschaft est la moins peuplée ( 81 habitants au $\mathrm{km}^{2}$ ).

\section{Population active potentielle (population des 15-64 ans)}

Malgré la comparabilité parfois limitée des sources de données, on peut tirer quelques conclusions sur le taux de participation (population active en pourcentage de la population active potentielle).C'est dans le Limbourg belge que ce taux est le plus élevé $(63,1 \%)$ suivi du Limbourg du Sud, de la Deutschsprachige Gemeinschaft et de la Province de Liège (tous autour de 55\%). La Regio Aachen semble avoir un taux de participation inférieur $(44,1 \%)$, mais la source utilisée ne permet pas une comparaison avec les autres parties de l'Eurégio. Le taux de participation des jeunes (population des 15-24 ans) est plus élevé dans le Limbourg belge que dans le Limbourg du Sud. On ne dispose pas, pour les autres composantes eurégionales, de données comparables concernant le taux de participation des jeunes. Le taux de participation des plus âgés (population des 55-64 ans) dans les parties de l'Eurégio pour lesquelles des données sont disponibles, se situe autour de $20 \%$.

Les types d'emploi de la population laborieuse (emploi fixe, travail flexible, indépendants etc.) sont très difficilement comparables à cause de l'utilisation de données différentes et des variantes nationales de définition. Dans la Regio Aachen, la part des fonctionnaires et des indépendants semblent inférieure à celle de certaines composantes de l'Eurégio. Les types d'emploi dans lesquels les jeunes sont actifs, 
ne peuvent pas non plus être comparés entre les différentes parties de l'Eurégio. En ce qui concerne les types d'emploi des plus âgés, on ne note pas de grandes différences entre les parties eurégionales pour lesquelles des données sont disponibles.

Dans toutes les composantes de l'Eurégio disposant de données spécifiques sur le travail à temps complet ou partiel selon le sexe, les femmes travaillent à temps partiel plus souvent que les hommes. C'est dans le Limbourg du Sud que le pourcentage de la population travaillant à temps partiel est le plus élevé $(32,5 \%)$; dans les autres parties de l'Eurégio ce taux se situe entre 10 et $20 \%$.

\section{Contexte macro-économique}

Dans toutes les composantes de l'Eurégio on constate une faible croissance du produit régional brut réel (PRB) pour la période 1985-1992 et un léger recul pour 1993. Quelques petites différences apparaissent entre les parties de l'Eurégio quant aux taux de croissance du PRB réel pour la période 1988-1993. On trouve le taux de croissance le plus faible dans le Limbourg belge (0,8\%); le plus élevé dans la Regio Aachen (2\%). C'est la même chose pour les taux de croissance de 1992-1993. Pour cette période les taux de croissance divergent peu: la baisse la plus forte est celle du PRB de la Province de Liège $(-2,7 \%)$; la plus faible, celle des PRB du Limbourg belge et du Limbourg du Sud $(-1,5 \%)$.

Le schéma sectoriel de croissance économique est explicité dans le tableau 1.

Tableau 1

Croissance du produit régional brut par secteur, 1988-1993 et 1992-1993 par composante eurégionale.

\begin{tabular}{|c|c|c|c|c|c|c|c|c|c|c|}
\hline \multirow[b]{2}{*}{ Secteur } & \multicolumn{2}{|c|}{ Limbourg du Sud } & \multicolumn{2}{|c|}{ Prov. de Liège } & \multicolumn{2}{|c|}{ Limbourg Belge } & \multicolumn{2}{|c|}{ Deutschspr. Gem. } & \multicolumn{2}{|c|}{ Regio Aachen } \\
\hline & 88-93 & $92-93$ & $88-93$ & $92-93$ & $88-93$ & $92-93$ & 8893 & $92-93$ & $88-93$ & $92-93$ \\
\hline $\begin{array}{l}\text { Agriculture/ } \\
\text { Sylviculture/ } \\
\text { pêche }\end{array}$ & + & 0 & + & ++ & ++ & ++ & $*$ & * & -- & -- \\
\hline $\begin{array}{l}\text { Industrie et bâti- } \\
\text { ment }\end{array}$ & -- & -- & + & - & - & - - & * & * & - & -- \\
\hline Services & ++ & 0 & + & - & + & 0 & * & * & ++ & ++ \\
\hline $\begin{array}{l}\text { Employé de } \\
\text { banque }\end{array}$ & + & ++ & ++ & ++ & ++ & ++ & * & * & * & * \\
\hline
\end{tabular}

\footnotetext{
-- baisse de plus de $3 \%$

- baisse entre 1 et $3 \%$

0 modification entre $-1 \%$ et $+1 \%$

+ hausse entre $1 \%$ et $3 \%$

++ hausse de plus de $3 \%$

* indisponible
} 


\section{Population active}

Dans le Limbourg du Sud, la Province de Liège et la Regio Aachen, environ $30 \%$ de la population laborieuse travaille dans le secteur de l'industrie et du bâtiment. Dans le Limbourg belge, ce pourcentage est supérieur $(36,4 \%)$, tandis que, dans cette région, le secteur des services est moins important $(60,4 \%)$. Les personnes actives dans le secteur des services sont bien plus nombreuses dans la Province de Liège $(69,0 \%)$. Le pourcentage d'emplois de ce secteur est également assez élevé dans la Deutschsprachige Gemeinschaft. Le secteur de l'agriculture et de la pêche est minime dans toutes les parties de l'Eurégio: le taux de population active dans ce secteur varie de $1,3 \%$ dans le Limbourg du Sud à 3,2\% dans le Limbourg belge.

La répartition sectorielle de l'emploi se reflète quelque peu dans la part de certaines professions parmi la population active. Ainsi, la part des professions s'exerçant dans l'industrie est plus importante dans le Limbourg belge que dans la Province de Liège (respectivement $32,8 \%$ et $23,3 \%$ ). Par contre, les métiers du secteur des services sont plus nombreux dans la province de Liège que dans le Limbourg belge.

Les actifs n'ayant suivi que l'enseignement primaire se rencontrent plus souvent dans le Limbourg du Sud que dans le Limbourg belge $(9,9 \%$ contre $7,0 \%)$. Parmi la population active, le pourcentage de ceux qui ont suivi un enseignement supérieur (universitaire ou non-universitaire) est d'environ $20 \%$ dans les régions pour lesquelles des données sont disponibles.

Dans le Limbourg du Sud, les femmes enregistrées comme chômeuses sont relativement nombreuses dans les catégories professionnelles "commerce", "bureau" et "hôtel, restaurant café". On trouve, dans le Limbourg du Sud, beaucoup d'hommes chômeurs enregistrés parmi les catégories professionnelles "personnel de production", "métallurgie" et "transport". Dans la Province de Liège, parmi les chômeurs enregistrés, les femmes sont plus nombreuses que les hommes. On y trouve beaucoup de femmes au chômage dans les catégories professionnelles "vendeurs", bureau" et "serveurs". Les catégories professionnelles "métallurgie", "bâtiment" et "professions libérales - techniciens et assimilés" comptent une grande part d'hommes chômeurs enregistrés.

Dans le Limbourg belge également, les femmes sont sur-représentées dans le chômage enregistré. Les femmes au chômage relèvent fréquemment des catégories professionnelles "ouvrier de la confection", "vendeur" et "gardien d'immeuble et personnel de nettoyage". Les hommes au chômage se rencontrent le plus souvent dans les catégories professionnelles "métallurgiste", "manoeuvre" et "ouvrier du bâtiment". Dans la Regio Aachen, de nombreux chômeurs enregistrés relèvent des catégories professionnelles "administration et bureau", "service général" et "trafic".

La part des chômeurs enregistrés n'ayant suivi que l'enseignement primaire est bien plus importante dans la Province de Liège et le Limbourg belge (pour les deux $30 \%$ 
environ) que dans le Limbourg du Sud et la Regio Aachen, où environ $20 \%$ des chômeurs enregistrés n'ont suivi que l'enseignement primaire. C'est dans la Regio Aachen, talonné par le Limbourg du Sud, que la part des chômeurs ayant une formation universitaire est la plus forte. II ressort des données réunies que, dans les deux dernières régions nommées, les chômeurs ont, en moyenne, un niveau d'enseignement plus élevé que dans le Limbourg belge et la Province de Liège.

\section{Marché du travail}

Il y a en moyenne dans le Limbourg du Sud, 23 chômeurs pour un emploi vacant enregistré. Les catégories professionnelles à problème (catégorie professionnelles avec un grand nombre de chômeurs par emploi vacant) sont les catégories "personnel de production" (124 chômeurs par emploi vacant), "manutentionnaire" (39 chômeurs par emploi vacant), et "enseignement" (37 chômeurs par emploi vacant). Dans le Limbourg belge il y a pour chaque emploi vacant une moyenne de 19 chômeurs. Les plus grands problèmes se rencontrent dans les catégories professionnelles "ouvrier de la confection", "artiste", et "personnel des media et autres" (respectivement 280, 160, et 113 chômeurs par emploi vacant). Dans la Deutschsprachige Gemeinschaft, il y a en moyenne 13 chômeurs enregistrés par emploi vacant. Des problèmes semblent se présenter dans les catégories professionnelles "professions de service", "professions de bureau" et "vente". Ces chiffres doivent être interprétés avec toute la prudence nécessaire en raison du petit nombre de chômeurs et d'emplois vacants dans cette région. Dans la Regio Aachen, il y a en moyenne 13 chômeurs par emploi vacant. Les problèmes se posent ici pour les catégories professionnelles "ouvrier de l'industrie céramique et de l'industrie du verre", "travailleur de la chimie" et "monteurs et professions de la métallurgie".

La figure 1 présente une comparaison des résultats de placements des agences pour l'empoi dans les différentes parties eurégionales. Le taux de placement est, dans le Limbourg du Sud, légèrement plus bas que dans le Limbourg belge. Dans le Limbourg du Sud, la plupart des emplois vacants sont pourvus dans l'industrie $(75,7 \%)$, c'est, par contre, dans le secteur de l'agriculture et de la pêche, où traditionnellement sont employés beaucoup de travailleurs saisonniers, que le taux de placement est le plus faible $(61,7 \%)$. Dans le Limbourg belge, les différences entre les secteurs sont bien plus importantes.

Par exemple, le taux de placement dans le secteur de l'agriculture, de la chasse et de la pêche n'y est que de $40,3 \%$. Des taux de placement supérieurs à $90 \%$ se rencontrent plusieurs fois (par exemple dans des secteurs tels que la chimie, les machines-outils, et les institutions sociales ou de charité). Dans le Limbourg du Sud le taux de placement le plus élevé se trouve dans la catégorie professionnelle "personnel de production"; les emplois vacants dans la catégorie "cadres" sont les moins bien pourvus $(41,8 \%)$. Le Limbourg belge connaît un taux de placement élevé dans la catégorie "paramédical et soins" $(89,7 \%)$; en revanche, son taux le plus faible se trouve dans la catégorie "agriculteur et pêcheur" (39,9\%). Pour la Province 
de Liège et la Deutschsprachige Gemeinschaft, on ne dispose que de taux de placement globaux de respectivement $72,3 \%$ et $73,5 \%$.

Figure 1

Résultats des placements par branche industrielle et catégorie professionnelle: taux de placement globaux, supérieurs et inférieurs.

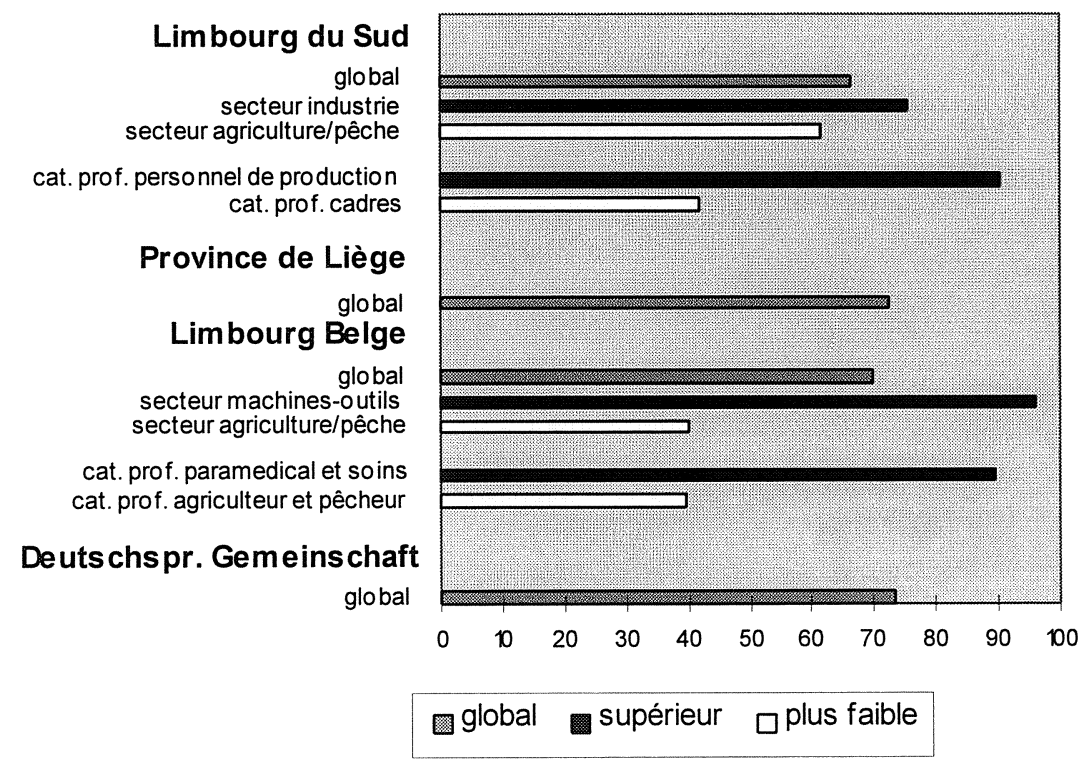




\section{Resümee}

\section{Bevölkerung}

Die Einwohnerzahl der Euregio belief sich am 1. Januar 1995 auf insgesamt 3.751.627. Aus der Bevölkerungsstruktur der Euregio geht hervor, daß die Vergreisung in der Region Aachen am stärksten fortgeschritten ist. Der Anteil der Altersgruppe zwischen 0 und 24 Jahren ist in dieser Region am geringsten vertreten. Die Altersgruppe ab 45 Jahren ist in der Region Aachen hingegen überdurchschnittlich besetzt, während sie in der belgischen Provinz Limburg vergleichsweise klein ist.

Der Ausländeranteil der Gesamtbevölkerung variiert erheblich in den einzelnen Regionen der Euregio. In Süd-Limburg sind beispielsweise 5,4\% der Bevölkerung ausländischer Herkunft, während sich der Ausländeranteil in der Deutschsprachigen Gemeinschaft auf $15,6 \%$ beläuft. Die Städte in der Euregio unterscheiden sich in dieser Hinsicht ebenfalls erheblich voneinander: In Genk sind 24,2\% der Bevölkerung Ausländer, während der Ausländeranteil in Sankt Vith lediglich 3,5\% beträgt.

Süd-Limburg ist mit 822 Einwohnern je $\mathrm{km}^{2}$ die dichtstbesiedelte Region der Euregio. In allen übrigen Regionen der Euregio ist die Bevölkerungsdichte wesentlich niedriger: Die Region Aachen hat eine Bevölkerungsdichte von 349 Einwohnern je $\mathrm{km}^{2}$, in Belgisch Limburg leben im Schnitt je km 319 Einwohner, die Provinz Liège hat eine Bevölkerungsdichte von 263 Einwohnern je $\mathrm{km}^{2}$, und die Deutschsprachige Gemeinschaft ist mit 81 Einwohnern je $\mathrm{km}^{2}$ am dünnsten besiedelt.

\section{Erwerbstätigenpotential (Einwohner im Alter von 15 bis 64 Jahren)}

Obwohl die herangezogenen Datenquellen in mancher Hinsicht nur bedingt miteinander vergleichbar sind, lassen sich daraus dennoch einige Schlußfolgerungen über den Beschäftigungsgrad (d. h. die Erwerbstätigen in Prozenten des Erwerbstätigenpotentials) ziehen. In Belgisch Limburg ist der Beschäftigungsgrad mit $63,1 \%$ am höchsten, gefolgt von Süd-Limburg, der Deutschsprachigen Gemeinschaft und der Provinz Liège (jeweils etwa 55\%). In der Region Aachen ist der Beschäftigungsgrad mit $44,1 \%$ anscheinend geringer, doch das zugrundeliegende Datenmaterial schließt einen Vergleich mit den übrigen Regionen der Euregio aus. Der Beschäftigungsgrad Jugendlicher (d. h. Einwohner im Alter von 15 bis 24 Jahren) ist in Belgisch Limburg höher als in Süd-Limburg. Für die übrigen Regionen der Euregio liegen keine vergleichbaren Daten über die Beschäftigung Jugendlicher vor. Der Beschäftigungsgrad älterer Bürger (d. h. Einwohner im Alter von 55 bis 64 Jahren) liegt in den Regionen der Euregio, für die einschlägige Daten vorliegen, bei etwa $20 \%$.

Ein Vergleich der Daten über die Art der Beschäftigung der berufstätigen Bevölkerung (Angestellte, Zeitarbeiter, Selbständige usw.) wird insbesondere dadurch erschwert, daß dem Datenmaterial verschiedene Quellen zugrunde liegen und keine 
gebietsübergreifend einheitlichen Definitionen vorliegen. In der Region Aachen ist der Anteil Beamter und Selbständiger anscheinend kleiner als in einigen anderen Regionen der Euregio. Ein Vergleich der Art der Beschäftigung Jugendlicher in den verschiedenen Regionen der Euregio ist ebenfalls nicht möglich. Aus den verfügbaren Daten über die Art der Beschäftigung älterer Bürger scheint hervorzugehen, daß sich die verschiedenen Regionen der Euregio in dieser Hinsicht nur unwesentlich voneinander unterscheiden.

In allen Regionen der Euregio, für die sich die Daten über Vollzeit- und Teilzeitbeschäftigung nach Geschlecht aufgliedern lassen, sind Frauen häufiger im Teilzeitverhältnis beschäftigt als Männer. In Süd-Limburg ist der Anteil der Teilzeitbeschäftigten an der berufstätigen Bevölkerung mit 32,5\% am größten, während in den übrigen Regionen der Euregio $10 \%$ bis $20 \%$ der Erwerbstätigen einer Beschäftigung im Teilzeitverhältnis nachgehen.

\section{Makroökonomische Hintergründe}

In allen Regionen der Euregio ist das reale regionale Bruttosozialprodukt im Zeitraum von 1985 bis 1992 leicht angestiegen und im Jahre 1993 leicht zurückgegangen. Die Wachstumsraten des realen regionalen Bruttosozialprodukts der einzelnen Regionen der Euregio in der Zeit von 1988 bis 1993 varieren nur geringfügig. Mit $0,8 \%$ hatte Belgisch Limburg die niedrigste Wachstumsrate, während die Wachstumsrate in der Region Aachen mit 2,0\% am höchsten war. Letzteres gilt gleichermaßen für die Wachstumsraten im Zeitraum 1992 bis 1993: Auch in diesem Zeitraum gab es kaum Wachstumsunterschiede, wobei das reale regionale Bruttosozialprodukt in der Provinz Liège mit $-2,7 \%$ am stärksten und in den belgischen und niederländischen Provinzen Limburg mit $-1,5 \%$ am geringsten zurückging.

Der Anteil der verschiedenen Wirtschaftssektoren am Wirtschaftswachstum wird in Tabelle 1 dargestellt. 
Tabelle 1

Wachstumsrate des regionalen Bruttosozialprodukts der einzelnen Regionen der Euregio je Wirtschaftssektor in den Zeiträumen 1988 bis 1993 und 1992 bis 1993.

\begin{tabular}{|c|c|c|c|c|c|c|c|c|c|c|}
\hline & \multicolumn{2}{|c|}{ Süd-Limburg } & \multicolumn{2}{|c|}{ Provinz Liège } & \multicolumn{2}{|c|}{ Belgisch Limburg } & \multicolumn{2}{|c|}{ Deutschspr. Gem. } & \multicolumn{2}{|c|}{ Region Aachen } \\
\hline $\begin{array}{l}\text { Wirtschaftsek- } \\
\text { tor }\end{array}$ & $88-93$ & $92-93$ & $88-93$ & $92-93$ & 8893 & $92-93$ & $88-93$ & $92-93$ & $88-93$ & $92-93$ \\
\hline $\begin{array}{l}\text { Land- und } \\
\text { Forstwirtschaft, } \\
\text { Fischerei }\end{array}$ & + & 0 & + & ++ & ++ & ++ & $\star$ & * & - & -- \\
\hline $\begin{array}{l}\text { Industrie und } \\
\text { Baugewerbe }\end{array}$ & 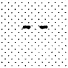 & - & + & - & - & - & ^ & * & + & - \\
\hline Dienstleistungen & ++ & 0 & + & - & + & 0 & 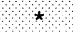 & * & ++ & ++ \\
\hline Bankwesen & + & ++ & ++ & ++ & ++ & ++ & $\approx$ & * & • & * \\
\hline
\end{tabular}

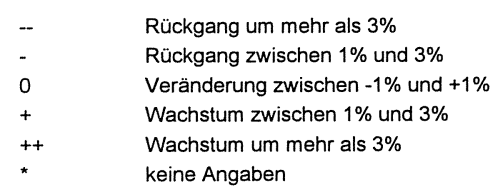

\section{Berufstätige Bevölkerung}

In Süd-Limburg, der Provinz Liège und der Region Aachen ist etwa 30\% der erwerbstätigen Bevölkerung in der Industrie und im Baugewerbe tätig. In Belgisch Limburg ist dieser Anteil mit 36,4\% ein wenig größer, während der Dienstleistungssektor in dieser Region mit $60,4 \%$ kleiner ist. In der Provinz Liège sind erheblich mehr Erwerbstätige im Dienstleistungsbereich tätig (69,0\%). Auch in der Deutschsprachigen Gemeinschaft ist der Anteil dieses Wirtschaftssektors an der Beschäftigung vergleichsweise groß. Der Sektor Landwirtschaft und Fischerei ist in allen Regionen der Euregio klein: Der Anteil der Erwerbstätigen in diesem Wirtschaftssektor variiert von 1,3\% in Süd-Limburg bis zu 3,2\% in Belgisch Limburg.

Der Anteil der verschiedenen Wirtschaftssektoren an der Beschäftigung spiegelt sich gewissermaßen in der Verteilung bestimmter Berufsgruppen in der berufstätigen Bevölkerung wider. Der Anteil der für die Industrie kennzeichnenden Berufe ist in Belgisch Limburg beispielsweise größer als in der Provinz Liège $(32,8 \%$ gegenüber $23,3 \%$ ). Berufe, die für den Dienstleistungsbereich kennzeichnend sind, findet man hingegen häufiger in der Provinz Liège als in Belgisch Limburg.

In Süd-Limburg haben mehr Berufstätige lediglich die Grundschule abgeschlossen als in Belgisch Limburg (9,9\% gegenüber 7,0\%). Der Anteil hochqualifizierter Bürger (d. h. mit Hochschul- oder Fachhochschulabschluß) an der berufstätigen Bevölkerung liegt in den Regionen, für die einschlägige Daten vorliegen, bei etwa $20 \%$.

In Süd-Limburg haben sich verhältnismäßig viele Frauen beim Arbeitsamt angemel- 
det, die eine Stelle als kaufmännische Angestellte, als Büroangestellte oder im Hotel- und Gaststättengewerbe suchen. Viele der arbeitslosen Männer in SüdLimburg suchen Arbeit in Produktionsbetrieben, in der Metallindustrie oder im Transportwesen. In der Provinz Liège sind mehr Frauen als Männer arbeitslos; in dieser Region suchen viele arbeitslose Frauen Arbeit als Verkäuferin, Büroangestellte oder Serviererin, während ein Großteil der arbeitslosen Männer in der Metallindustrie, im Baugewerbe oder in der Berufskategorie "Freiberufler - techniker und gleichgestellter" Arbeit sucht.

In Belgisch Limburg sind ebenfalls überdurchschnittlich viele Frauen arbeitslos. Sie suchen in der Regel Arbeit in der Bekleidungsindustrie, als Verkäuferin, Haushälterin oder Raumpflegerin. Bei den arbeitslosen Männern sind Stellengesuche für Metallarbeiter, Handlanger und Bauarbeiter am häufigsten. Viele Arbeitslose in der Region Aachen suchen Arbeit als Büroangestellte oder im Dienstleistungssektor und im Verkehrswesen.

Der Anteil Arbeitsloser, die lediglich die Grundschule abgeschlossen haben, ist in der Provinz Liège und in Belgisch Limburg (jeweils etwa 30\%) erheblich größer als in Süd-Limburg und der Region Aachen, wo jeweils etwa $20 \%$ der erfaßten Arbeitslosen lediglich die Grundschule abgeschlossen haben. Der Anteil Arbeitsloser mit Hochschulabschluß ist in der Region Aachen am größten, gefolgt von Süd-Limburg. Aus den herangezogenen Daten geht außerdem hervor, daß die Arbeitslosen in den beiden letztgenannten Regionen in der Regel eine bessere Schul- oder Berufsausbildung abgeschlossen haben als die Arbeitslosen in den beiden Regionen Belgisch Limburg und der Provinz Liège.

\section{Arbeitsmarkt}

In Süd-Limburg kommen auf jede beim Arbeitsamt angemeldete offene Stelle im Schnitt 23 Arbeitslose. Problembereiche auf dem Arbeitsmarkt (d. h. Berufsgruppen mit einer großen Anzahl Arbeitsloser je offene Stelle) sind Produktionsbetriebe (124 Arbeitslose je offene Stelle), Lagerverwaltung (39 Arbeitslose je offene Stelle) und das Schulwesen (37 Arbeitslose je offene Stelle). In Belgisch Limburg kommen auf jede offene Stelle im Schnitt 19 Arbeitslose. Zu den größten Engpässen kommt es beim Stellenangebot in der Bekleidungsindustrie, bei Künstlern, in der Medienbranche und bei sonstigem Personal (jeweils 280, 160 und 113 Arbeitslose je offene Stelle). In der Deutschsprachigen Gemeinschaft kommen auf jede offene Stelle im Schnitt 13 Arbeitslose. Die Berufsgruppen "Dienstleistungen", "Bürotätigkeiten" und "Verkauf" sind anscheinend problematisch. Angesichts der niedrigen Arbeitslosenzahl und weniger offener Stellen in dieser Region ist bei der Interpretation dieser Zahlen jedoch mit Vorsicht vorzugehen. In der Region Aachen kommen auf jede offene Stelle 13 Arbeitslose. Hier lauten die problematischen Berufsgruppen "Keramik- und Glasarbeiter", "Chemiearbeiter" und "Monteure und Metallarbeiter".

In Abbildung 1 werden die Vermittlungsergebnisse der Arbeitsämter in den verschie- 
denen Teilen der Euregio miteinander verglichen. Der Besetzungsanteil offener Stellen ist in Süd-Limburg ein wenig niedriger als in Belgisch Limburg. In Süd-Limburg werden die meisten offenen Stellen in der Industrie besetzt $(75,7 \%)$, während der Besetzungsanteil im Wirtschaftssektor Landwirtschaft und Fischerei, in dem traditionsgemäß überwiegend mit Saisonarbeitern gearbeitet wird, am niedrigsten ist $(61,7 \%)$. In Belgisch Limburg unterscheiden sich die Wirtschaftssektoren erheblich mehr voneinander. So beträgt der Besetzungsanteil im Sektor Landwirtschaft, Jagd und Fischerei lediglich 40,3\%. Besetzungsanteile über $90 \%$ kommen einige Male vor (z. B. in den Wirtschaftssektoren Chemie, Maschinenfertigung und soziale und wohltätige Einrichtungen). In Süd-Limburg ist der Besetzungsanteil in den Berufsgruppen "Produktionsmitarbeiter" am höchsten; offene Stellen aus der Berufsgruppe "leitende Funktionen" werden am schlechtesten vermittelt (41,8\%). In Belgisch Limburg ist der Besetzungsanteil in der Berufsgruppe "medizinische Hilfsberufe und Krankenpflege" überaus groß $(89,7)$; dahingegen ist der Besetzungsanteil in der Berufsgruppe "Landwirt und Fischer" am niedrigsten (39,9\%). Für die Provinz Liège und die Deutschsprachige Gemeinschaft liegen lediglich Gesamtzahlen der Besetzungsanteile vor: Sie betragen jeweils $72,3 \%$ und $73,5 \%$.

\section{Abbildung 1}

Vermittlungen je Wirtschaftssektor und Berufsgruppe: Gesamtzahl, höchste und niedrigste Besetzungsanteile

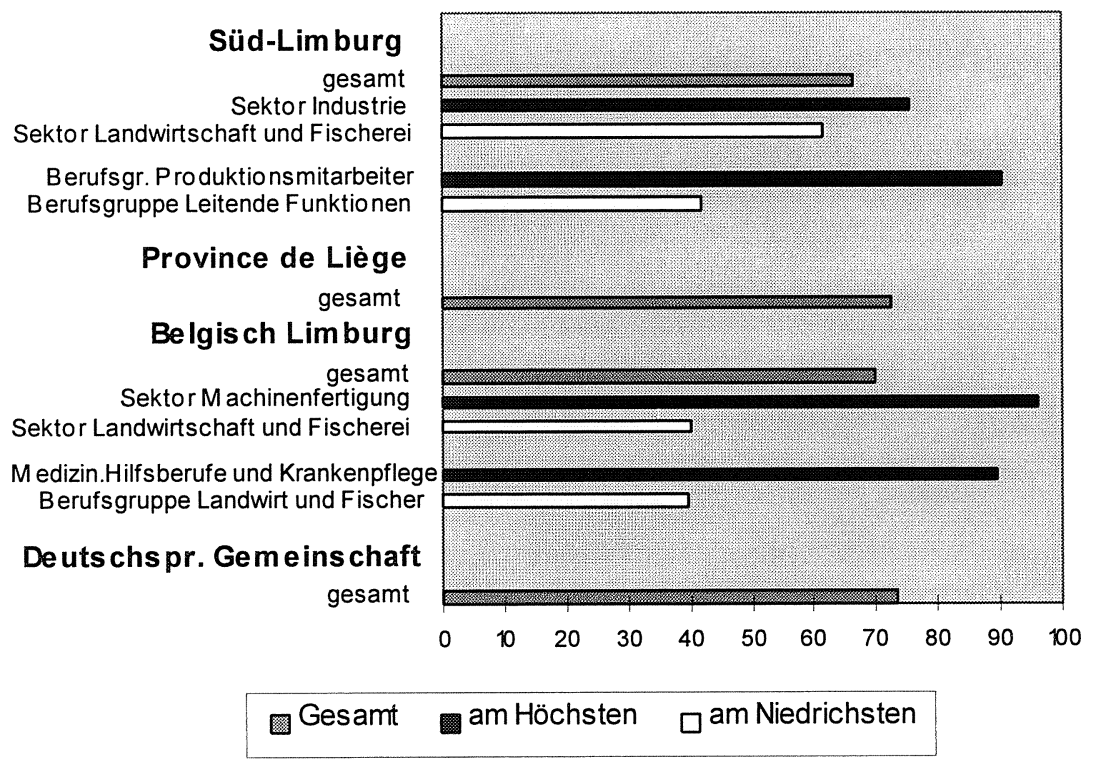





\section{Inhoud}

Bladzijde

Resumé

Voorwoord

Inleiding

1 Bevolking

1.A Totale bevolking

1.A.1 Opbouw van de bevolking naar leeftijd

1.A.2 Aandeel van andere nationaliteiten in de bevolking

1.A.3 Bevolking grote steden en percentage andere nationaliteiten

1.A.4 Bevolkingsdichtheid per gemeente in personen per vierkante kilometer

1.A.5 Ontwikkeling van de bevolking 1990-1995

1.B Potentiële beroepsbevolking: bevolking 15-64

1.B.1 Participatie index van de bevolking van 15-64 jaar

1.B.2 Typen werkgelegenheid van de werkzame bevolking van 15-64 jaar

1.B.3 Deeltijd- en voltijdarbeid

1.C Jongeren: bevolking 15-24 jaar

1.C.1 Participatie-index van de jongeren

1.C.2 Typen werkgelegenheid van de jongeren

1.C. 3 Deeltijd- en voltijdarbeid van de jongeren

1.D Oudere bevolking: bevolking 55-64 jaar

1.D.1 Participatie-index van de oudere bevolking 73

1.D.2 Typen werkgelegenheid van de oudere bevolking 76

1.D.3 Deeltijd- en voltijdarbeid van de oudere bevolking 79

2 Macro-economische achtergrond $\quad 81$

$\begin{array}{lll}2.1 & \text { Bruto regionaal produkt } & 87\end{array}$

2.2 Economische groei: per sector en voor de gehele economie 91

2.3 Investeringsquote per sector en voor de gehele economie 95

2.4 Productiviteits-indices per sector en voor de gehele economie 96

3 Beroepsbevolking $\quad 97$

3.1 Werkzame bevolking naar bedrijfstak 103

$\begin{array}{ll}3.2 \text { Werkzame bevolking ingedeeld naar beroepscategorie } & 109\end{array}$

3.3 Onderwijsachtergrond van de werkzame beroepsbevolking van 15-64 jaar $\quad 114$

$\begin{array}{lll}3.4 & \text { Geregistreerde werklozen naar beroepscategorie } & 119\end{array}$ 
3.5 Geregistreerde werklozen naar hoogst genoten type onderwijs

3.7 Typen werkgelegenheid van de werkzame bevolking van 15-64 jaar, per sector

4 Arbeidsmarkt

4.1 Actuele vraag- en aanbod verhoudingen op de arbeidsmarkt: werklozen en vacatures

4.2 Ingediende en vervulde vacatures: bemiddelingsresultaten per bedrijfssector en bedrijfstak

4.3 Ingediende en vervulde vacatures: bemiddelingsresultaten per beroepscategorie

4.4 Beroepenprognose

5 Aansluiting onderwijs-arbeidsmarkt

5.1 Uitstroom uit onderwijs: geslaagden voortgezet en hoger onderwijs 159

5.2 Bestemming van uitstromers uit het onderwijs per opleidingsrichting 164

5.3 Aansluiting vooropleiding-vervolgopleiding en vooropleiding-werk 166

$\begin{array}{llr}\text { Bijlage } 1 & \text { Definities } & 167\end{array}$

Bijlage $2 \quad$ Bestuurlijke en administratieve indeling van de Euregio 173

Bijlage $3 \quad$ Gebruikte afkortingen $\quad 179$ 


\section{Contenu}

Resumé

Avant-propos

Introduction

1.A Population totale

1.A.1 Répartition par âge: (si possible série chronologique)

1.A.2 Part des autres nationalités dans la population

1.A.3 Population des villes plus importantes, part des autres nationalités

1.A.4 Densité de population par commune

1.A.5 Developpement de la population 1990-1995

1.B Population active potentielle: population des 15-64 ans

1.B.1 Indice de participation: actif, chômeur, inactif

1.B.2 Types d'emploi: actifs: employé, travail souple, travailleur indépendant, autre

1.B.3 Travail à temps complet ou partiel

1.C Jeunes: population des $15-24$ ans

1.C. 1 Indice de participation

1.C.2 Types d'emploi

1.C.3 Travail à temps complet ou partiel $\quad 65$

1.D Seniors: population des 55-64 ans $\quad 69$

1.D.1 Indice de participation $\quad 73$

1.D.2 Types d'emploi $\quad 76$

1.D.3 Travail à temps complet ou partiel $\quad 79$

2 Contexte macro-economique 83

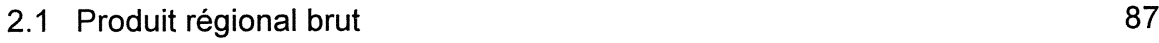

2.2 Indices conjoncturels en totalité et par secteur 91

2.3 Taux d'investissement en totalité et par secteur 95

2.4 Indices de productivité en totalité et par secteur 96

3 Population active $\quad 99$

3.1 Population laborieuse selon la branche industrielle 103

3.2 Population laborieuse selon la catégorie professionnelle 109

3.3 Population laborieuse selon le type d'enseignement le plus suivi $\quad 114$

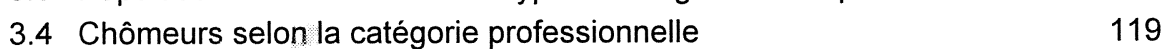

3.5 Chômeurs selon le type d'enseignement le plus suivi 126

$\begin{array}{lll}3.6 & \text { Pourcentage de chômeurs dans les villes plus importantes } & 131\end{array}$ 
4 Marche du travail $\quad 135$

4.1 Rapports actuels de l'offre et de la demande: offres $\begin{array}{ll}\text { d'emploi/demandeurs d'emploi } & 139\end{array}$

4.2 Offres d'emploi satisfaites: résultats des placements par secteur et branche industrielle

4.3 Offres d'emploi satisfaites: résultats des placemente par catégorie professionnelle

4.4 Prévisions de l'accroissement de la demande par profession

5 Coordination enseignement-marche du travail

5.1 Nombre des diplômés de l'enseignement; éventuellement, fichier de la dernière année de l'enseignement

5.2 Destination du flux de l'enseignement selon le type d'enseignement

5.3 Coordination qualitative entre l'enseignement et la profession selon

Annexe 1 Definitions 


\section{Inhalt}

Resümee

Vorwort

ix

Einleitung

xxix

1 Bevölkerung 5

1.A Bevölkerung insgesamt 5

1.A.1 Bevölkerung insgesamt, Altersaufbau (indem möglich Zeitspanne) 7

1.A.2 Anteil anderer Nationalitäten in der Bevölkerung 12

1.A.3 Bevölkerung größere Städte, Anteil anderer Nationalitäten 19

1.A.4 Bevölkeringsdichte pro Gemeinde 20

1.A.5 Entwicklung der Bevölkerung 1990-1995 29

1.B Potentielle Berufsbevölkerung: Bevölkerung Altersklasse 15-64 Jahre 35

1.B.1 Teilnehmerindex: beschäftigt, arbeitslos, nicht aktiv 37

1.B.2 Beschäftigungstypen: Beschäftigte nach Arbeitnehmern, $\begin{array}{ll}\text { Selbständigen oder übrigen } & 42\end{array}$

1.B.3 Vollzeit- und Teilzeitarbeit $\quad 47$

1.C Jugendliche: Bevölkerung Altersklasse 15-24 Jahre 57

$\begin{array}{ll}\text { 1.C.1 Teilnehmerindex } & 59\end{array}$

1.C.2 Beschäftigungstypen $\quad 62$

$\begin{array}{ll}\text { 1.C.3 Vollzeit- und Teilzetarbeit } & 67\end{array}$

1.D Senioren: Bevölkerung Altersklasse 55-64 Jahre 71

$\begin{array}{ll}\text { 1.D.1 Teilnehmerindex } & 73\end{array}$

$\begin{array}{ll}\text { 1.D. } 2 \text { Beschäftigungstypen } & 76\end{array}$

$\begin{array}{ll}\text { 1.D.3 Vollzeit- und Teilzeitarbeit } & 79\end{array}$

2 Makroökonomische Hintergrund $\quad 85$

$\begin{array}{ll}2.1 \text { Regionales Bruttosozialprodukt } & 87\end{array}$

2.2 Konjunkturindizien: insgesamt und nach jeweiligen Sektoren 91

$\begin{array}{ll}2.3 \text { Investitionsquote pro Sektor } & 95\end{array}$

2.4 Produktivitätsindizien nach Sektor und insgesamt 96

3 Berufsbevölkerung 101

3.1 Erwerbstätige Bevölkerung nach Erwerbszweig 103

$\begin{array}{ll}3.2 \text { Erwerbstätige Bevölkerung nach Berufsgruppe } & 109\end{array}$

3.3 Erwerbstätige Bevölkerung nach höchstem Ausbildungsniveau 114

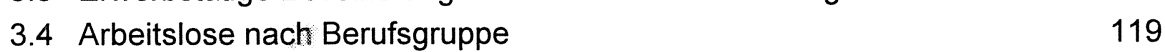

$\begin{array}{ll}3.5 & \text { Arbeitslose nach höchstem Ausbildungsniveau } \\ & 126\end{array}$

3.6 Prozentsatz Arbeitslose in großen Städten und ggf. in den 
3.7 Beschäftigte pro Sektor nach Art der Beschäftigung 132

4 Arbeitsmarkt $\quad 137$

4.1 Aktuelle Verhältnisse zwischen Nachfrage und Angebot: Offene Stellen gegenüber Arbeitssuchenden $\quad 139$

4.2 Besetzung von offenen Stellen: Vermittlungsergebnisse pro Sektor und Erwerbszweige

4.3 Besetzung von offenen Stellen: Vermittlungsergebnisse pro Berufsgruppe

4.4 Nachfrageprognosen

5 Anschluß von der Ausbildung an den Arbeitsmarkt 157

5.1 Anzahl Abiturienten der Schultypen 159

5.2 Bestimmung des Austritts aus den Schultypen 164

5.3 Qualitativer Anschluß von Ausbildung an den Beruf nach
Ausbildungstyp

$\begin{array}{lll}\text { Anlage } 1 \quad \text { Definitionen } & 171\end{array}$

$\begin{array}{lll}\text { Anlage } 2 & \text { Administrative Gliederung } & 173\end{array}$

$\begin{array}{lll}\text { Anlage } 3 & \text { Abkürzungen } & 179\end{array}$ 


\section{Voorwoord}

De Euregio Maas-Rijn is een gebied met een geschiedenis van grote problemen op economisch en sociaal vlak, maar ook een gebied met een groot potentieel voor verdere economische ontwikkeling. Een deel van de Euregio heeft een landelijk karakter, maar er liggen ook enige van de oudste industriële zônes in deze contreien, zoals rond Liège en Maastricht. In alle delen van de Euregio hebben de diverse vormen van mijnbouw en delfstoffenwinning een groot stempel gedrukt op de structuur van de werkgelegenheid, het patroon van stedelijke ontwikkeling en het landschap. Het zijn juist de sectoren van bedrijvigheid die in de Euregio sterk vertegenwoordigd waren, de zware industrie en mijnbouw, die in de afgelopen decennia onder grote druk kwamen te staan. De mijnbouw is vrijwel verdwenen, de zware industrie sterk achteruit gegaan. Die neergang heeft een spoor van werkloosheid en daaraan gerelateerde sociale problematiek achtergelaten. Mede door de eenzijdige samenstelling van de beroepsbevolking kwam de ontwikkeling van vervangende werkgelegenheid niet onmiddelijk op gang.

Inmiddels ontwikkelen verschillende euregiodelen zich voorspoedig; voor sommigen kan zelfs niet of nauwelijks meer van een achterstandssituatie worden gesproken. Die ontwikkeling is mede tot stand gekomen door de gerichte en planmatige inzet van overheidsmiddelen in het kader van de diverse reconversie-programma's; ontwikkelingsmaatschappijen in verschillende vorm hebben daarbij een belangrijke rol gespeeld.

Een belangrijk aspect van deze ontwikkeling dat ook van groot belang is voor de toekomstige ontwikkeling, is de positie als grensregio. Traditioneel was de positie als perifeer gebied een nadeel in de economische en sociale ontwikkeling. Door het geleidelijke wegvallen van de binnengrenzen in de Europese Unie en de algemene tendens tot internationalisering van de economie kan dit nadeel in een voordeel veranderen. De Euregio Maas-Rijn, voorheen aangrenzende perifere gebieden binnen de grenzen van hun eigen land, kan zich ontwikkelen tot een belangrijke economische regio binnen de EU.

De vorming van de Euregio Maas-Rijn is mede bedoeld om de ontwikkelingsmogelijkheden in verband met de 'van nature' internationale oriëntatie van de Euregiodelen optimaal te benutten en zo bij te dragen aan het inlopen en verdwijnen van de uit het verleden georven achterstanden. Doel van de Euregio is immers mede het bevorderen van de economische ontwikkeling van de Euregio als geheel en van de afzonderlijke delen van de Euregio.

Een goed functionerende arbeidsmarkt is een voorwaarde voor deze ontwikkeling. Een optimale aansluiting van het onderwijs op de arbeidsmarkt, zowel in kwalitatief als in kwantitatief opzicht, is hierbij van groot belang. Door hun ligging heeft de 
arbeidsmarkt in de afzonderlijke grensregio's vaak een veel kleinere schaal dan in de regio's die verder van de landsgrenzen verwijderd liggen. Daardoor is er een minder goede aansluiting tussen de verschillende soorten vragers en aanbieders op de arbeidsmarkt en is er sprake van een aanzienlijke grotere pendel met en mobiliteit naar de aangrenzende gebieden binnen de eigen landsgrens dan de arbeidsmobiliteit over de landsgrenzen heen, ook al gaat het in het laatste geval om een veel geringere geografische afstand ${ }^{1}$.

Een goede informatievoorziening over de ontwikkelingen op de arbeidsmarkt kan sterk bijdragen aan een betere werking van de arbeidsmarkt. Zowel de marktpartijen als de intermediaire organisaties en betrokken overheden kunnen op basis van Euregionale arbeidsmarktinformatie komen tot een meer optimale besluitvorming.

\section{Initiatief tot het Overzicht}

Het Researchcentrum voor Onderwijs en Arbeidsmarkt (ROA) levert reeds enige jaren een bijdrage aan het vergroten van de transparantie van de Nederlandse arbeidsmarkt, vooral door het onderhouden van een informatiesysteem onderwijsarbeidsmarkt. Daartoe in staat gesteld door een subsidie van het ministerie van Onderwijs, Cultuur en Wetenschappen, directie Beroepsonderwijs en Volwasseneneducatie BVE, heeft het ROA het initiatief genomen tot de ontwikkeling van een informatiesysteem onderwijs-arbeidsmarkt voor de Euregio Maas - Rijn. Aanvankelijk is een verkennende studie uitgevoerd naar de mogelijke behoeften aan en mogelijkheden tot een informatiesysteem ${ }^{2}$. Op basis van de uitkomsten van deze verkenning is het initiatief genomen tot de daadwerkelijke ontwikkeling van een eerste versie van dit informatiesysteem.

Daarbij heeft van meet af aan voorop gestaan dat de ontwikkeling van een informatiesysteem slechts zin zou hebben indien dit in nauwe samenwerking zou geschieden met organisaties binnen de Euregio die belang hebben bij gerichte informatie over de euregionale arbeidsmarkt, en op basis daarvan een actieve eigen inbreng in de ontwikkeling en de voortzetting van het systeem zouden kunnen hebben. Vanuit dit gezichtspunt heeft het ROA gestreefd naar een samenwerkingsverband waarin uit ieder euregiodeel tenminste één partner vertegenwoordigd is. Daarbij is vooral gezocht naar partners met een eigen taakstelling ten aanzien van de arbeidsmarkt c.q. de informatievoorziening omtrent de arbeidsmarkt.

1. J.W. van Dam, A. de Grip en J.A.M. Heijke, Naar een euregionale arbeidsmarkt MaasRijn, in: Economisch Statistische Berichten. 77e jaargang, nr. 3853, 1 april 1992, pp. 321324.

2. U. Teunis, Informatiesysteem onderwijs - arbeidsmarkt voor de Euregio Maas-Rijn, ROAR-1995/2, Maastricht 1995. 
Initiatiefgroep

Op basis van dit initiatief is in april 1996 een Initiatiefgroep tot stand gekomen, bestaande uit organisaties die ieder voor eigen verantwoordelijkheid een bijdrage leveren aan deze eerste versie van het Euregionaal Overzicht Ondenwijs-Arbeidsmarkt en die een gezamelijke verantwoordelijkheid willen nemen voor de verdere ontwikkeling ervan. Deze organisaties, en de voornaamste contactpersonen daarbinnen, zijn:

* Deutschsprachige Gemeinschaft Belgien: Arbeitsmarkt Beobachtungsstelle Ostbelgien ABEO. Dit is een initiatief van de arbeidsvoorzieningsorganisatie FOREM, de Industrie- und Handelskammer IHK, Subregionale Ausschuß Berufsbildung und Arbeitsbeschaffung SABA, Conseil Economique Wallon en de Wirtschafts Förderungs Gesellschaft. De ABEO inventariseert en bundelt beschikbare informatie ten behoeve van de dragende instellingen. ABEO heeft zorggedragen voor een zo volledig mogelijke bijdrage aan het Overzicht, waarbij diverse statistische bronnen zijn aangesproken. Contactpersoon voor ABEO is de heer Johanns (FOREM St. Vith); in de initiatiefgroep participeren ook de heren Nelles en Weynand (FOREM) en Hennes (SABA).

* Province de Liège: FOREM Liège. Vanuit zijn taakstelling met betrekking tot het verstrekken van informatie over de arbeidsmarkt neemt FOREM Liège deel. Daarbij is ook informatie verzameld over de beide andere subregionale directies binnen de province de Liège. De informatieverzameling was wel beperkt door de beschikbare gegevensbronnen. Aanvullende informatieverzameling voor deze regio is daarom uitgevoerd door het ROA en het Steunpunt WAV (zie hieronder). Contactpersonen voor FOREM zijn mevrouw Vanbockestal (Service des Relations Internationales) en de heer Desaintes (economist).

* Provincie Limburg (België): het arbeidsmarktobservatorium AMO. Dit is een initiatief van de Permanente Werkgroep Limburg, de VDAB en het Subregionaal Tewerkstellingscomité Limburg. Het AMO is ondergebracht bij de VDAB te Genk. Doel van het project is vooral een betere verkenning van de vraag naar arbeid en knelpunten in de aansluiting tussen vraag en aanbod, met het oog op een gericht opleidings-, begeleidings- en toeleidingsbeleid. In dat verband vindt ook een inventarisatie en verzameling van statistisch materiaal plaats. Dit onderdeel van het project is uitgevoerd door Steunpunt WAV te Leuven. Ook worden gegevens gebruikt van de studiedienst van de VDAB. Contactpersonen zijn de heer Martens (projectcoördinator), mevrouw Cremers (databemiddelaar) en de heer Van Wichelen (Steunpunt WAV).

* Regio Aachen: het Landesarbeitsamt. Hoewel het Duitse deel van de Euregio, Regio Aachen, slechts een deel van het werkterrein van het Landesarbeitsamt 
Nordrhein-Westfalen vormt, was deze instantie bereid tot medewerking vanuit zijn taakstelling tot beschikbaarstelling van informatie over de arbeidsmarkt. Daarbij kon vooral informatie ter beschikking worden gesteld op basis van gegevens vanuit de arbeidsvoorzieningsorganisatie. Aanvullende gegevensverzameling is door het ROA uitgevoerd. Contactpersonen zijn hier mevrouw Klippenstein en de heer Sandten (Referat Arbeitsmarkt- und Berufsforschung).

* Zuid-Limburg: Researchcentrum voor Onderwijs en Arbeidsmarkt ROA. Het ROA heeft zelf de informatieverzameling met betrekking tot Zuid-Limburg uitgevoerd. Daarbij kon worden voortgebouwd op andere projecten op het vlak van de regionale arbeidsmarkt. Tevens is arbeidsmarktinformatie aangeleverd door het RBA Limburg. Het ROA heeft voorts het project als geheel gecoördineerd en zorg gedragen voor bundeling van de bijdragen, de begeleidende tekst, waar nodig aanvullende verzameling en bewerking van gegevens over de andere Euregiodelen en voor de publicatie van het Overzicht. De projectleiding, alsmede het voorzitterschap van de initiatiefgroep, is bij het ROA in handen van de heer De Grip. De overige contactpersonen zijn hier de heer Teunis (coördinatie) en de heer Van Loo (dataverwerking).

Naast genoemde instanties nemen, voorlopig in de rol van waarnemer, deel de Stichting Euregio Maas-Rijn en het EURES - crossborder project binnen de Euregio Maas-Rijn. De initiatiefgroep wordt nadrukkelijk gezien als een open netwerk, waaraan iedere organisatie kan deelnemen die een eigen inbreng in het informatiesysteem kan en wil hebben.

leder van de samenwerkingspartners draagt de volledige verantwoordelijkheid voor zijn specifieke bijdragen aan het Euregionaal Overzicht. 


\section{Avant-propos}

La région Meuse - Rhin a un passé d'importants problèmes économiques et sociaux mais c'est aussi une région présentant un fort potentiel de développement économique. Si une partie de l'Eurégion offre un caractère rural, on rencontre aussi certaines des plus anciennes zones d'industries comme aux environs de Liège et de Maastricht. Partout les différentes formes de l'industrie minière et d'extraction des minéraux ont laissé leurs empreintes sur la structure du marché du travail, sur le développement urbain et sur le paysage. Les secteurs d'activités comme l'industrie lourde et l'industrie minière étaient fortement représentés et ce sont précisément ces secteurs qui ont connu, ces dernières décennies, de très gros problèmes. L'activité minière a pratiquement disparu et l'industrie lourde a connu une très importante récession. Ce déclin a laissé derrière lui le sous-emploi et son cortège de problèmes sociaux. La composition de la population active, orientée prépondérant vers les industries en récession, a été un frein à la mise en place d'activités de remplacement.

A l'heure actuelle, certaines parties de l'Eurégion se développent très rapidement et, pour certaines on ne peut plus ou à peine parler de retard. Ce résultat a été atteint aussi grâce aux actions méthodiques entreprises par les autorités dans le cadre de divers programmes de reconversion; les sociétés de développement dans leurs différentes formes ont, ici, joué un rôle important.

Un aspect important pour le développement actuel et pour le développement futur est la situation de région frontalière. Traditionnellement, une situation périphérique est défavorable à l'évolution économique et sociale. Cet handicap peut se transformer en avantage grâce à la disparition progressive des frontières dans l'union Européenne et à la tendance générale à l'internationalisation de l'économie. Auparavant ensemble de régions voisines mais périphériques à l'intérieur des frontières de leur pays respectif, l'Eurégion peut devenir une importante région économique au sein de l'UE.

La formation de l'Eurégion Meuse-Rhin a pour objectif de mettre à profit le caractère "naturellement" international de la région et de contribuer ainsi à combler le retard hérité du passé. Le but de l'Eurégion est de soutenir le développement économique de la région tant dans ses parties que dans son ensemble.

Un marché du travail fonctionnant correctement est une condition à cette évolution. Une coordination optimale entre l'enseignement et le marché du travail, tant sur le plan quantitatif que sur le plan qualitatif, est d'une grande importance. La situation frontalière fait que le marché du travail dans les différentes parties de la région est plus restreint que celui des régions intérieures. Ceci a pour conséquence une moins bonne adéquation entre les différentes offres et demandes du marché du travail et 
I'on constate plus de migrations pendulaires et de mobilité à l'intérieur des frontières nationales qu'au dessus des frontières même si, dans ce cas, la distance géographique est moindre ${ }^{3}$.

Une meilleure information sur l'évolution du marché du travail contribuerait fortement à l'amélioration de ce dernier. Que ce soit pour les acteurs du marché, pour les organisations intermédiaires ou pour les autorités concernées, une meilleure information eurégionale portant sur le marché du travail aboutirait à une meilleure prise de décision.

\section{Initiative du Plan d'ensemble}

Le 'Researchcentrum voor Onderwijs en Arbeidsmarkt' (ROA) travaille, depuis quelques années déjà, à l'amélioration de la transparence du marché du travail néerlandais, ceci en s'occupant surtout d'un système d'information sur l'enseignement et la vie active. Une subvention du ministère de l'éducation, de la culture et des sciences, direction de l'enseignement professionnel et de l'enseignement pour adultes BVE, a permis au ROA de prendre l'initiative d'établir un système d'information enseignement-marché du travail pour l'Eurégion. Préalablement une étude ${ }^{4}$ avait analysé l'utilité d'un tel système et les possibilités de le constituer. Les résultats de l'étude ont mené à la réalisation de la première version de ce système d'informations.

Tout d'abord il a été décidé que l'élaboration d'un tel système ne serait utile que si celle-ci se faisait en étroite collaboration avec les organisations intéressées par une information sur le marché de l'emploi eurégional. Ces organisations devraient de plus participer activement à la constitution et à la progression du système. Partant de ce point de vue le ROA a cherché à s'assurer la collaboration de chacune des parties de la région, chaque partie ayant au moins un représentant. On a surtout recherché des participants ayant une fonction concernant le marché de l'emploi, ici une fonction d'information.

\section{Groupe d'initiative}

A partir de cette idée on a créé en avril 1996 un groupe d'initiative formé de différentes organisations qui participent a cette première version du Plan d'ensemble eurégional Enseignement - Marché du Travail à leur propre compte et qui veulent coopérer à son développement ultérieur.

3. J.W. van Dam, A. de Grip et J.A.M. Heijke, Naar een euregionale arbeidsmarkt Maas-Rijn, in: Economisch Statistische Berichten 77 année, nr 3853, 1 avril 1992, pp 321-324.

4. U Teunis, informatiesysteem onderwijs-arbeidsmarkt voor de Euregio Maas-Rijn, ROA-R1995/2, Maastricht 1995.

vi 
Ces organisations et leurs représentants principaux sont:

* Deutschsprachige Gemeinschaft Belgien: Arbeitsmarkt Beobachtungsstelle Ostbelgien ABEO. C'est une initiative du Service de l'Emploi FOREM, Industrieund Handelskammer IHK, Subregionale Ausschuß Berufsbildung und Arbeitsbeschaffung SABA, Conseil Economique Wallon et le Wirtschafs Förderungs Gesellschaft. Le ABEO inventorie et regroupe les informations disponibles au profit des organismes responsables. ABEO s'est efforcé d'exploiter au maximum les sources statistiques pour le Plan d'ensemble. Le représentant pour l'ABEO est monsieur Johanns (FOREM st. Vith); participent également au groupe d'initiative messieurs Nelles et Weynand (FOREM) et monsieur Hennes (SABA).

* Province de Liège: FOREM Liège. Le FOREM fournit des informations sur le marché du travail et, à partir de cette fonction, participe au projet. Des informations provenant de deux autres directions sous-régionales de la province de Liège sont également répertoriées. Le nombre d'informations répertoriées est restreint vues les sources disponibles. Des informations complémentaires sont donc recueillies par le ROA et le Steunpunt WAV (voir ci-dessous). Les représentants pour le FOREM sont madame Vanbockestal (Service des Relations Internationales) et monsieur Desaintes (économiste).

* Province Limbourg (Belgique): arbeidsmarktobservatorium AMO. C'est une initiative du Permanente Werkgroep Limburg et du Subregionaal Tewerkstellingscomité Limburg. Le AMO dépend du VDAB à Gand. Le but de ce projet est une meilleure connaissance de la demande d'emploi et des distorsions entre la demande et l'offre et d'utiliser celle-ci pour une politique de formation, de conseil et de suivi professionnel. Pour cela on inventorie et regroupe du matériel statistique. Cette partie du projet est le fait du Steunpunt WAV à Louvain. Donneés du "Studiedienst VDAB" sont aussi utilisées. Les représentants sont monsieur Martens (coordonnateur du projet), madame Cremers (données) et monsieur Van Wichelen (Steunpunt WAV).

* Region Aix La Chapelle: das landesarbeitsamt. Bien que la partie allemande de l'Eurégion, région d'Aix La Chapelle, ne soit que l'une des composantes du terrain de travail de Landesarbeitsamt Nordrhein-Westfalen, cette organisation a accepté de participer au groupe sur la base de sa tâche d'information concernant le marché de l'emploi. Les informations disponibles proviennent des organisations s'occupant des services de l'emploi. Le ROA recueille des données supplémentaires. Les représentants sont madame Klippenstein et monsieur Sandten (Referat Arbeitsmarkt- und Berufsforschung).

* Limbourg-Sud: Researchcentrum voor Onderwijs en Arbeidsmarkt ROA. Le ROA a lui-même recueilli les informations concernant le Limbourg-Sud. II a été le 
coordonnateur du projet et s'est chargé de regrouper les différents apports, d'écrire les textes d'accompagnement et, où cela était nécessaire, il a cherché des informations complémentaires et travaillé sur des données portant sur d'autres parties de la région. Le ROA a publié le Plan d'ensemble. La direction du projet ainsi que la direction du groupe d'initiative sont assurées, pour le ROA, par monsieur De Grip. Les autres représentants sont monsieur Teunis (coordination) et monsieur Van Loo (travail sur données).

Outre les organisations citées ci-dessus, participent aussi au projet, provisoirement en tant qu'auditeurs, la Fondation Eurégion Meuse-Rhin et I'EURES- projet transfrontalier dans la région Meuse-Rhin. Le groupe d'initiative veut être un réseau ouvert à toute organisation qui voudrait et pourrait contribuer au système d'information.

Chaque participant porte l'entière responsabilité de son apport au Plan d'ensemble Eurégional. 


\section{Vorwort}

Die Euregio Maas-Rhein ist ein Gebiet mit einer Vielzahl großer wirtschaftlicher wie sozialer Probleme, jedoch auch ein Gebiet mit einem umfangreichen Potential für eine wirtschaftliche Weiterentwicklung. Ein Teil der Euregio ist ländlich geprägt, aber man trift hier auch einige der ältesten Industriebereiche in diesen Landstrichen wie z.B. in der Umgebung von Lüttich und Maastricht. In allen Gebieten der Euregio haben die verschiedenen Formen von Bergbauaktivitäten und Mineraliengewinnung die Struktur der Beschäftigung, das Modell der städtischen Entwicklung und die Landschaft stark geprägt. Es sind gerade diese Sektoren des Gewerbes, nämlich die Schwerindustrie und Bergbau, die in der Euregio stark vertreten waren und in den vergangenen Jahrzehnten unter großen Druck gesetzt wurden. Der Bergbau ist nahezu verschwunden und die Schwerindustrie ist stark zurückgegangen. Dieser Niedergang hat eine Spur von Arbeitslosigkeit und eine damit in Zusammenhang stehende soziale Problematik hinterlassen. Infolge der einseitigen Zusammensetzung der Berufsbevölkerung kam die Entwicklung von Ersatzarbeitsplätzen nicht unmittelbar in Gang.

Inzwischen entwickeln sich die verschiedenen Teilgebiete der Euregio günstig und bei einigen kann auch nicht oder kaum mehr von einer Rückstandssituation gesprochen werden. Die Entwicklung ist mit durch den gezielten und planmäßigen Einsatz von öffentlichen Mitteln im Rahmen der verschiedenen Wiederumstellungsprogramme zustandegekommen; Entwicklungsgesellschaften der verschiedensten Formen haben dabei eine wichtige Rolle gespielt.

Ein wichtiger Aspekt dieser Entwicklung, der auch für die Entwicklung in der Zukunft von Bedeutung ist, ist die Stellung als Grenzregion. In traditioneller Hinsicht war die Stellung als ein peripheres Gebiet ein Nachteil in der wirtschaftlichen und sozialen Entwicklung. Durch das allmähliche Wegfallen der Landesgrenzen in der Europäischen Union und der allgemeinen Tendenz zur Internationalisierung der Wirtschaft kann sich dieser Nachteil in einen Vorteil verändern. Die Euregio Maas-Rhein, ehemals aneinandergrenzende periphere Gebiete innerhalb der eigenen Landesgrenzen, kann sich zu einem wichtigen wirtschaftlichen Gebiet innerhalb der EU entwickeln.

Die Bildung der Euregio Maas-Rhein will auch erreichen, daß Entwicklungsmöglichkeiten im Zusammenhang mit der "natürlichen" internationalen Ausrichtung der Euregiogebiete optimal genutzt werden und somit zum Aufholen und Verschwinden von aus der Vergangenheit hinterbliebenen Rückstände beigetragen wird. Ziel der Euregio ist dann ja auch die Förderung der wirtschaftlichen Entwicklungen der Euregio als Ganzes und ihrer separaten Teilgebiete.

Ein gut funktionierender Arbeitsmarkt ist eine Bedingung für diese Entwicklung. Ein 
bestmöglicher Anschluß von der Ausbildung an den Arbeitsmarkt sowohl in qualitativer wie in quantitativer Hinsicht ist hier von äußerster Wichtigkeit. Der Arbeitsmarkt hat durch seine Lage in den separaten Grenzregionen oft einen viel kleineren Umfang als in den Regionen, die weiter von den Landesgrenzen entfernt liegen. Deshalb ist der Anschluß zwischen den verschiedenen Arten von Angebot und Nachfrage auf dem Arbeitsmarkt weniger gut und ist auch die Pendel mit und Umzug nach den angrenzenden Gebieten innerhalb der eigenen Landesgrenzen größer als die grenzüberschreitende Arbeitsmobilität, obgleich es sich in diesem letzten Fall handelt um viel geringere geographische Entfernungen ${ }^{5}$.

Eine gute Informierung über die Entwicklungen auf dem Arbeitsmarkt kann viel zu einem besseren Funktionieren des Arbeitsmarktes beitragen. Sowohl die Marktparteien sowie die Zwischeninstanzen und betroffenen Behörden können auf der Grundlage von euregionaler Arbeitsmarktinformation $\mathrm{zu}$ einer besseren Beschlußfassung kommen.

\section{Initiative zur Übersicht}

Das 'Researchcentrum voor Onderwijs en Arbeidsmarkt' - (ROA) (Forschungszentrum für Ausbildung und Arbeitsmarkt) liefert bereits seit einigen Jahren einen Beitrag zur Vergrößerung der Transparenz des niederländischen Arbeitsmarktes, insbesondere durch die Aufrechterhaltung eines Informationssystems betriffs Ausbildung und Arbeitsmarkt. Das ROA hat die Initiative zur Entwicklung eines Informationssystems 'Ausbildung und Arbeitsmarkt' für die Euregio Maas-Rhein dank einer Unterstützung des niederländischen Kultusministeriums, Abteilung Berufsschulung und Erwachsenenbildung BVE, ergreifen können. Zu Beginn wurde der mögliche Bedarf an einem Informationssystem ${ }^{6}$ sowie die Möglichkeiten eines solchen Systems untersucht. Auf der Ergebnisgrundlage dieser Untersuchung wurde die Initiative zur tatsächlichen Entwicklung einer ersten Fassung dieses Informationssystems ergriffen.

Von Anfang an hat dabei an erster Stelle gestanden, daß die Entwicklung eines Informationssystems eigentlich nur dann sinnvoll ist, wenn diese in enger Zusammenarbeit mit Organisationen innerhalb der Euregio stattfindet, die an gezielter Information über den euregionalen Arbeitsmarkt Interesse haben, und die auf dieser Grundlage einen aktiven Beitrag zur Entwicklung und Fortsetzung des Systems leisten können. Von diesem Gesichtspunkt aus betrachtet, strebte das ROA nach einer Arbeitsgemeinschaft, in der aus jedem Euregiogebiet mindestens ein Partner

5. J.W. van Dam, A. de Grip en J.A.M. Heijke, Naar een euregionale arbeidsmarkt Maas-Rijn, in: Economische Statistische Berichten. 77. Jahrgang, Nr. 3853, 1. April 1992, S. 321-324.

6. U. Teunis, Informatiesysteem onderwijs - arbeidsmarkt voor de Euregio Maas-Rijn, ROA-R1995/2, Maastricht, 1995. 
vertreten ist. Dabei wurde vor allem nach Partnern, die eine eigene Aufgabenstellung in bezug auf den Arbeitsmarkt bzw. auf die Informierung über den Arbeitsmarkt haben, gesucht.

Initiativgruppe

Auf der Grundlage dieser Initiative ist im April 1996 eine Initiativgruppe zustande gekommen, die aus Organisationen besteht, die jede auf ihre eigene Verantwortung einen Beitrag zu dieser ersten Fassung der Euregionalen Übersicht 'Ausbildung und Arbeitsmarkt' leistet und die eine gemeinsame Verantwortung für die weitere Entwicklung übernehmen will.

Diese Organisationen und die wichtigsten Kontaktpersonen derselben sind:

* Deutschsprachige Gemeinschaft Belgien: Arbeitsmarkt Beobachtungsstelle Ostbelgien ABEO. Das ist eine Initiative von der Arbeitsverwaltung FOREM, der Industrie- und Handelskammer IHK, dem subregionalen Ausschuß Berufsbildung und Arbeitsbeschaffung SABA und dem Conseil Economique Wallon sowie der Wirtschafts-Förderungsgesellschaft. Die ABEO inventarisiert und sammelt verfügbare Informationen zugunsten der Trägerinstitutionen. Die ABEO hat einen möglichst vollständigen Beitrag zur Übersicht geleistet, wobei verschiedene statistische Quellen herangezogen wurden. Die Kontaktperson für ABEO ist Herr Johanns (FOREM St. Vith); in der Initiativgruppe nehmen auch die Herren Nelles und Weynand (FOREM) und Hennes (SABA) teil.

* Provinz Lüttich: FOREM Lüttich. Die Arbeitsverwaltung FOREM nimmt aufgrund ihrer Aufgabenstellung - Verschaffung von Informationen über den Arbeitsmarkt an der Übersicht teil. Dabei wurden auch Informationen über die beiden anderen subregionalen Verwaltungen in der Provinz Lüttich gesammelt. Die Sammlung der Informationen wurde durch die zur Verfügung stehenden Datenquellen sehr beschränkt. Eine ergänzende Informationssammlung dieser Gebiete wurde deshalb vom ROA und vom Stützpunkt WAV (siehe nachstehend) durchgeführt. Die Kontaktpersonen für FOREM sind Frau Vanbockestal (Service des Relations Internationales) und Herr Desaintes (Volkswirt).

* Provinz Limburg (Belgien): Arbeitsmarktobservatorium AMO. Hier handelt es sich um eine Initiative der 'Permanente Werkgroep Limburg' (ständige Arbeitsgruppe Limburg) und des 'Subregionaal Tewerkstellingscomité Limburg' (subregionaler Arbeitsbeschaffungsausschuß Limburg). Das AMO steht unter der Verwaltung von der VDAB in Genk. Das Ziel dieses Projektes ist vor allem eine bessere Erforschung der Arbeitsnachfrage und der Engpässe im Anschluß zwischen Angebot und Nachfrage in Hinblick auf eine gezielte Ausbildungs-, Betreuungsund Zuführungspolitik. In diesem Zusammenhang findet auch die Inventarisierung und Sammlung von statistischem Material statt. Dieser Teil des Projekts wird vom 
Stützpunkt WAV in Leuven durchgeführt. Auch werden Daten des "Studiedienst VDAB" benützt. Die Kontaktpersonen sind Herr Martens (Projektkoordination), Frau Cremers (Datenvermittlerin) und Herr Van Wichelen (Stützpunkt WAV).

* Regio Aachen, Landesarbeitsamt: Obwohl der deutsche Teil der Euregio, die Regio Aachen, nur einen Teil des Tätigkeitsgebietes des Landesarbeitsamtes Nordrhein-Westfalen bildet, war diese Instanz aufgrund ihrer Aufgabenstellung (zur Verfügung stellen von Informationen über den Arbeitsmarkt) zur Mitarbeit bereit. Dabei konnten vor allem Informationen auf der Grundlage von Daten der Arbeitsverwaltung zur Verfügung gestellt werden. Das ROA hat eine ergänzende Datensammlung durchgeführt. Die Kontaktpersonen sind hier Frau Klippenstein und Herr Sandten (Referat Arbeitsmarkt- und Berufsforschung).

* Südlimburg, Researchcentrum voor Onderwijs en Arbeidsmarkt ROA (Forschungszentrum für Ausbildung und Arbeitsmarkt). Das ROA hat die Sammlung von Informationen über Südlimburg selbst vorgenommen, wobei auf anderen Projekten auf dem Gebiet des regionalen Arbeitsmarktes aufgebaut werden konnte. Gleichzeitig wurden die Informationen über den Arbeitsmarkt vom RBA Limburg zur Verfügung gestellt. Das ROA hat ferner das Projekt als Ganzes koordiniert und für die Koppelung der Beiträge, den begleitenden Text, die eventuell ergänzende Sammlung und Bearbeitung der Daten der anderen Euregiogebiete und für die Publikation der Übersicht gesorgt. Die Projektleitung sowie der Vorsitz der Initiativgruppe ist bei ROA in Händen von Herrn De Grip. Die übrigen Kontaktpersonen sind hier die Herren Teunis (Koordination) und Van Loo (Datenverarbeitung).

Neben den aufgeführten Instanzen nehmen die Stiftung Euregio Maas-Rhein und EURES - ein grenzüberschreitendes Projekt innerhalb der Euregio Maas-Rhein daran vorläufig als Beobachter teil. Die Initiativgruppe wird nachdrücklich als ein offenes Netzwerk angesehen, woran jede Organisation teilnehmen kann, die einen eigenen Beitrag zum Informationssystem leisten kann und will.

Jeder der Zusammenarbeitspartner trägt die volle Verantwortung für seine jeweiligen Beiträge zur Euregionalen Übersicht. 


\section{Inleiding}

\section{Doelen van het Euregionaal Overzicht}

Het Euregionaal Overzicht beoogt het verbeteren van de informatievoorziening in de Euregio over de arbeidsmarkt in het algemeen en de aansluiting tussen onderwijs en arbeidsmarkt in het bijzonder, tegen de achtergrond van demografische ontwikkelingen enerzijds en de macro-economische ontwikkeling anderszijds. Daartoe is per Euregiodeel overeenkomstige informatie verzameld en gebundeld in een makkelijk toegankelijke vorm.

Doel van het Euregionaal Overzicht is vooral de ondersteuning van de beleidsvorming en werkprocessen van instellingen en bedrijven in de Euregio, om daarmee bij te dragen aan de economische en sociale ontwikkeling van de Euregiodelen en van de Euregio als geheel. Op grond van ondermeer de verkennende studie wordt verwacht dat vooral de volgende typen instellingen en bedrijven profijt van het Euregionaal Overzicht zouden kunnen hebben:

1. Organisaties op het terrein van de arbeidsbemiddeling, zowel publieke (Arbeitsamt, VDAB/FOREM, RBA) als private (b.v. uitzendbureaus).

Voor deze doelgroep tracht het Euregionaal Overzicht vooral te voorzien in de behoefte aan meer algemene informatie over de euregionale ontwikkelingen met het oog op strategische besluitvorming op beleidsniveau (instellingsbeleid betreffende internationalisering), evaluatie van dit beleid, informatie over arbeidsmarktknelpunten ten behoeve van het scholingsbeleid en informatie over grensoverschrijdende mogelijkheden ten behoeve van het bemiddelingsbeleid. Wat betreft het scholingsen bemiddelingsbeleid heeft het Euregionaal Overzicht vooral een attenderende functie: het reikt mogelijkheden aan voor grensoverschrijdende scholingsprojecten, geeft aan waar eventuele grensoverschrijdende plaatsingsmogelijkheden te verwachten zijn enz. Het Euregionaal Overzicht fungeert hier naast de reeds bestaande informatiestroom tussen de arbeidsvoorzieningsdiensten, die met name betrekking heeft op de uitwisseling van openstaande vacatures. Het Euregionaal Overzicht vult deze aan waar het gaat om de grote lijnen, de achtergrondinformatie en -voorzover technisch mogelijk- de verwachtingen voor de nabije toekomst. Aangenomen mag worden dat naarmate het relatieve belang van grensoverschrijdende activiteiten toeneemt de behoefte aan gesystematiseerde informatie groter wordt.

2. Organisaties op het terrein van de studie- en beroepskeuzevoorlichting, zowel publieke (Arbeitsamt-Berufsberatung, PMS-centra, AOB) als private.

Deze doelgroep heeft vooral behoefte aan informatie ten behoeve van de voorlichting, advisering en begeleiding bij de keuzes van beroepsgerichte opleidingen. Het 
gaat dan met name om informatie over opleidingen waaraan in het omringende buitenland behoefte bestaat. In het algemeen wordt met dit criterium nog weinig rekening gehouden. Verwacht mag worden dat hier sprake is van een toenemende informatiebehoefte in verband met de internationalisering van de arbeidsmarkten. Met name op lager en middelbaar niveau gaat het bij deze internationalisering vooral om informatie over arbeidsmogelijkheden in het nabije buitenland, dus in dit geval binnen de Euregio.

3. Intermediaire organisaties op sociaal-economisch gebied, met name de diverse Kamers van ambacht, industrie en handel, branche- en sectororganisaties en regionale reconversie- en ontwikkelingsmaatschappijen (b.v. GOM, LIOF).

Bij deze intermediaire organisaties vloeit de behoefte aan Euregionale arbeidsmarktinformatie voort uit de grensoverschrijdende samenwerking en de formulering van het economisch structuurbeleid. Het Euregionaal Overzicht zou de taakstelling van deze organisaties op het terrein van de bevordering van economische ontwikkeling en werkgelegenheid kunnen ondersteunen. Naarmate het euregionaal aspect van deze taakstelling belangrijker wordt, bij voorbeeld door de opening van grensoverschrijdende bedrijfsterreinen, wordt de behoefte aan informatie groter.

4. Ondenwijsinstellingen, onderwijsautoriteiten, vooral op het terrein van het initieel beroepsonderwijs en specifieke vakgerichte scholing.

De behoefte aan euregionale informatie bij onderwijsinstellingen e.d. is gerelateerd aan de planning van opleidingen en cursussen met het oog op grensoverschrijdende mogelijkheden en het ontwerpen van opleidingsinhouden ten behoeve van deze mogelijkheden (bidiplomering, grensoverschrijdende stages e.d.). Op bescheiden schaal is hier al ervaring mee opgedaan. Te verwachten is dat systematische informatie zal wijzen op meer mogelijkheden, en omgekeerd dat een toenemende activiteit op dit terrein zal leiden tot een grotere behoefte aan informatie.

\section{Werkgevers, zowel private bedrijven als overheden en publieke diensten.}

Een manifeste informatiebehoefte is hier het verkennen van de mogelijkheden voor werving over de grens bij moeilijk vervulbare vacatures. Deze informatiebehoefte zal vooral liggen bij bedrijven die thans reeds van pendelaars gebruik maken. Verwacht mag worden dat deze informatiebehoefte zal toenemen indien meer werkgevers door het Euregionaal Overzicht op mogelijkheden van grensoverschrijdende werving worden geattendeerd. Het Euregionaal Overzicht zou ook de vestiging kunnen ondersteunen van grote (internationale) bedrijven, die door hun schaal op de internationale/euregionale arbeidsmarkt zijn aangewezen. 
6. Plaatselijke en regionale overheden: gemeenten, Kreise, arrondissementen, provincies; verder landelijke overheden voorzover het gaat om beleid betreffende de landsdelen in de Euregio.

Voor de diversen overheden zal de euregionale informatie vooral een rol kunnen spelen bij de ondersteuning van het economische structuurbeleid en het arbeidsmarktbeleid. Ook bij de evaluatie van dit beleid kan vergelijkende informatie van belang zijn. Naarmate het euregionale aspect van het beleid belangrijker wordt, b.v. bij grensoverschrijdende infrastructurele maatregelen, vestiging van bedrijfsterreinen, aantrekken van internationale bedrijfsvestigingen e.d., neemt het belang van deze informatie toe.

\section{Publieke functie.}

Internationalisering, de Euregio, pendel en grensarbeid: deze onderwerpen komen regelmatig in de publiciteit. De toenemende invloed van deze ontwikkelingen op het dagelijks leven vergroot, zeker in de grensregio's, de belangstelling bij de burgers. Dit leidt tot een informatievraag bij persorganen, andere media, voorlichtingsdiensten en particuliere personen. Deze informatiebehoefte is uiterst divers, want sterk aan actuele thema's gebonden. De voortdurende beschikbaarheid van systematische basisinformatie en een herkenbaar 'adres' waar deze te krijgen is zijn dan van belang. Ook voor de publieke bekendheid en aanvaarding van de Euregio-ontwikkeling is beschikbaarheid van goede informatie van belang.

\section{Vormgeving van het Euregionaal Overzicht}

Indicatoren

Het Euregionaal Overzicht Onderwijs-Arbeidsmarkt heeft zoveel mogelijk de vorm van een stelsel van indicatoren gekregen. Onder 'indicator' wordt hier verstaan een enkelvoudig of samengesteld gegeven dat een bepaald facet van de arbeidsmarkt of de aansluiting tussen onderwijs en arbeidsmarkt belicht. ledere indicator heeft een duidelijk eigen functie, die door zijn plaats binnen de structuur van het Euregionaal Overzicht en door vorm en naamgeving duidelijk is. Daarnaast zijn er indicatoren met de functie van achtergrondinformatie, nodig voor de juiste interpretatie van de andere indicatoren. De indicatoren hebben de vorm van tabellen, grafische representaties en/of kwalitatieve beschrijvingen volgens een vast stramien ('signalementen'). Bij sommige indicatoren zijn nadere toelichtingen en/of interpretaties gevoegd.

\section{Groepering gegevens; vergelijkbaarheid en volledigheid}

In het Euregionaal Overzicht worden alle gegevens gepresenteerd per Euregio-deel. De Euregio-delen zijn: (Nederlands) Zuid-Limburg, provincie Limburg (B.), province 
de Liège, de Deutschsprachige Gemeinschaft Belgiën en de Regio Aachen. Daarnaast worden enige gegevens gepresenteerd die betrekking hebben op de grotere steden in de Euregio.

Opgemerkt moet worden, dat de gegevens voor de Province de Liège vaak ook de Deutschsprachige Gemeinschaft bevatten. Dit wordt veroorzaakt doordat de Deutschsprachige Gemeinschaft deel uitmaakt van de Province de Liège. In de meeste statistieken kan deze regio niet verder geografisch gedesaggregeerd worden.

Gezien het gebruiksdoel (informatieverstrekking ten behoeve van de beleidsvorming en de concrete werkprocessen van instellingen binnen de Euregio) is een hoge prioriteit toegekend aan het verstrekken van een zo volledig mogelijk actueel beeld van de arbeidsmarktsituatie en -ontwikkelingen in ieder Euregiodeel. Aan de volledige vergelijkbaarheid van de gegevens is vooralsnog een geringere prioriteit toegekend. De bovengenoemde gebruiksdoelen impliceren immers dat het Euregionaal Overzicht niet in de eerste plaats zal worden gebruikt voor vergelijking tussen de Euregiodelen: een goed inzicht in de situatie per Euregiodeel staat voorop. Op onderdelen waar (voor één of meer Euregiodelen) geen vergelijkbare cijfers mogelijk zijn worden zo goed mogelijk passende cijfers gepresenteerd. Hetzelfde geldt voor de jaartallen waarop de gegevens betrekking hebben: zoveel mogelijk worden de meest recente cijfers gebruikt, ook indien het jaartal verschilt per Euregiodeel. Op grond van dezelfde overweging worden gegevens, die voor een bepaalde regio ontbreken, voor de andere wel ingevuld.

\section{Structuur en detail}

De genoemde gebruiksmogelijkheden vereisen in het algemeen gedetailleerde informatie. Teveel details gaan echter ten koste van de overzichtelijkheid. Op twee wijzen is de overzichtelijkheid en bruikbaarheid van het Euregionaal Overzicht bewaakt. Ten eerste maken de structuur van het Euregionaal Overzicht en de omschrijving van de indicatoren binnen deze structuur steeds de functie van de informatie duidelijk. Deze structuur maakt bovendien een gerichte selectie van informatie voor bepaalde gebruiksdoelen mogelijk. Ten tweede worden waar relevant samenvattende cijfers en grafieken gepresenteerd naast de meer gedetailleerde tabellen.

\section{Methodologische verantwoording}

De gegevens zijn per Euregiodeel verzameld en bewerkt door de leden van de initiatiefgroep (zie voorwoord). Dit impliceert dat de gehanteerde werkwijze en de gebruikte informatiebronnen per Euregiodeel kunnen verschillen. Het Euregionaal Overzicht bevat zowel gegevens die door de betreffende instelling zelf zijn verza- 
meld als gegevens afkomstig van nationale instellingen binnen de desbetreffende landen. Per indicator wordt telkens de bron vermeld.

In alle of vrijwel alle Euregiodelen zijn de volgende typen gegevensbronnen gebruikt:

* demografische statistieken op basis van de bevolkingsregistratie en/of volkstellingen;

* statistiek beroepsbevolking, op basis van enquêtes en/of volkstellingen;

* gegevens over de beroepsbevolking van de uitvoeringsorganen sociale zekerheid;

* registratie gegevens werkzoekenden en vacatures van de arbeidsvoorzieningsorganisaties;

* diverse gegevensbronnen over de macro-economische ontwikkeling, ondermeer de nationale rekeningen;

* onderwijsstatistieken, met name van de gediplomeerden per type onderwijs; voor Zuid-Limburg aangevuld met schoolverlatersonderzoek naar de bestemming van gediplomeerden.

In Bijlage 1 wordt een overzicht gegeven van de definities van de belangrijkste gehanteerde begrippen.

\section{Structuur van het overzicht}

In het navolgende worden de indicatoren, waaruit het Overzicht bestaat, beknopt omschreven. Uit deze omschrijvingen en de structuur van het Overzicht dient te blijken welke informatie aan de respectieve indicatoren kan worden ontleend.

\section{indicatorengroep 1: de bevolking}

Deze indicatoren hebben betrekking op de bevolking als geheel van de verschillende euregiodelen. Een aantal achtergrondgegevens wordt gepresenteerd: omvang en leeftijdsopbouw van de bevolking, aandeel andere nationaliteiten en bevolkingsdichtheid. Vervolgens wordt specifiek naar de typen bezigheden van de bevolking gekeken: de participatie aan arbeid of andere bezigheden (b.v. studerend) en van de werkenden de typen werkgelegenheid en de onderwijsachtergrond. Dit wordt voor drie categorieën gedaan: de bevolking van 15 - 64 jaar (d.i. de groep die beroepsmatig werkzaam kan zijn), de jongeren (15 - 24) en de senioren (55 - 64). De grenzen van deze leeftijdsgroepen kunnen per euregiodeel enigszins variëren.

\section{A totale bevolking}

1.A.1 opbouw van de bevolking naar leeftijd (zo mogelijk tijdreeks).

1.A.2 aandeel van andere nationaliteiten in de bevolking. 
1.A. 3 bevolking grotere steden en percentage andere nationaliteiten.

1.A.4 bevolkingsdichtheid per gemeente.

1.A.5 ontwikkeling van de bevolking 1990-1995.

1.B bevolking 15 - 64 jaar (potentiële beroepsbevolking)

1.B.1 participatie-index: werkend, werkloos, niet actief e.d..

1.B.2 typen werkgelegenheid: werknemer, flexibele arbeid, zelfstandig en overig.

1.B.3 deeltijd- en voltijdarbeid.

1.C bevolking 15 - 24 jaar (jongeren)

1.C.1 participatie-index.

1.C.2 typen werkgelegenheid.

1.C.3 deeltijd- en voltijdarbeid.

1.D bevolking 55 - 64 jaar (ouderen)

1.D.1 participatie-index.

1.D.2 typen werkgelegenheid.

1.D.3 deeltijd- en voltijdarbeid.

indicatorengroep 2: macro-economische achtergrondvariabelen

Hier gaat het om de indicatoren die een beeld geven van het economisch functioneren van de onderscheiden euregiodelen.

2.1 bruto regionaal product

2.2 economische groei: per sector en voor de gehele economie

2.3 investeringsquote per sector en totaal

2.4 productiviteitsindices per sector en voor de gehele economie

xviii 


\section{indicatorengroep 3: beroepsbevolking}

Hier wordt nader ingegaan op de beroepsbevolking, dus op het deel van de bevolking dat beroepsmatig actief is (werkzame bevolking) danwel werkzoekend is. Van de werkzame bevolking wordt gekeken naar de aard van de activiteiten per sector of (meer gedetailleerd) per bedrijfstak en per beroepscategorie en naar de onderwijsachtergrond.

3.1 werkzame bevolking naar bedrijfstak.

3.2 werkzame bevolking naar beroepscategorie.

3.3 werkzame bevolking naar hoogst genoten type onderwijs

3.4 werklozen naar beroepscategorie.

3.5 werklozen naar hoogst genoten type onderwijs.

3.6 percentage werklozen grotere steden.

3.7 werkzame bevolking per sector naar typen werkgelegenheid.

\section{indicatorengroep 4: arbeidsmarkt}

Deze groep indicatoren betreft de vraag - aanbodverhoudingen op de arbeidsmarkt, de knelpunten op de arbeidsmarkt en de bemiddeling; waar mogelijk worden prognoses omtrent de arbeidsmarkt opgenomen.

4.1 actuele vraag - aanbodverhoudingen op de arbeidsmarkt: werklozen en vacatures

4.2 ingediende en vervulde vacatures: bemiddelingsresultaten per bedrijfssector en bedrijfstak

4.3 ingediende en vervulde vacatures: bemiddelingsresultaten per beroepscategorie

\section{4 beroepenprognose}

\section{indicatorengroep 5: aans/uiting onderwijs - arbeidsmarkt}

Deze groep indicatoren betreft de overgang van het onderwijs naar de arbeidsmarkt. Gekeken wordt naar de 'output' van het initieel onderwijs, d.i. de onderwijssoorten met aansluiting op de arbeidsmarkt (al dan niet naast voorbereiding op verdere studie). Waar mogelijk worden gegevens over de overgang naar de arbeidsmarkt en de kwalitatieve aansluiting op de arbeidsmarkt gepresenteerd. 
5.1 uitstroom uit onderwijs: aantal geslaagden voortgezet en hoger onderwijs.

5.2 bestemming van uitstromers uit het onderwijs per opleidingsrichting.

5.3 aansluiting vooropleiding-vervolgopleiding en vooropleiding-werk. 


\section{Introduction}

\section{Objectifs du Plan d'ensemble eurégional}

Le Plan d'ensemble eurégional veut améliorer, dans l'Eurégion, les possibilités d'information sur le marché de l'emploi en général et en particulier sur la coordination enseignement-marché du travail, avec en arrière-plan d'un côté l'évolution démographique et d'un autre côté l'évolution macro-économique. A cette fin, les informations relevantes sont recueillies et rassemblées de manière très abordable.

Le but du Plan d'ensemble Eurégional est d'aider les organisations et les entreprises à décider de leurs politiques et de les assister pour leur travail dans l'Eurégion. Ceci pour contribuer au développement économique et social de la région dans son ensemble et dans ses parties. Vues les études préalables, il apparait que ce sont les entreprises et organisations suivantes qui pourraient tirer profit du Plan d'ensemble Eurégional:

1. Organisations dans le domaine du service de l'emploi, tant publiques (Arbeitsamt, VDAB/FOREM, RBA) que privées (p. ex. les agences d'intérim).

Pour ce groupe le Plan d'ensemble Eurégional essaye de répondre à la demande d'informations générales concernant les évolutions eurégionales, ceci pour les décisions stratégiques au niveau des politiques (politique des organisations en ce qui concerne l'internationalisation) et pour l'évaluation de ces politiques. Le Plan d'ensemble Eurégional peut fournir des informations sur les distortions du marché de l'emploi pour la politique de la formation et des informations sur les possibilités transfrontalières pour les politiques de placement. Pour les deux derniers cas le Plan d'ensemble Eurégional joue surtout un rôle de révélateur: il expose les possibilités de formation transfrontalier, indique quelles sont les possibilités de placement transfrontalier à attendre, etc. Le Plan d'ensemble Eurégional fonctionne ici à côté des échanges d'informations qui existent déjà entre les services pour l'emploi et qui concernent surtout les offres actuelles d'emploi non-satisfaites. Le Plan d'ensemble Eurégional complète ces informations par des informations de fond et par, autant que cela soit possible techniquement, des prévisions sur les évolutions à attendre dans un avenir proche. On peut penser que plus les activités transfrontalières prendront de l'importance, plus le besoin d'une information systématique sera présent.

2. Organisations privées ou publiques s'occupant d'orientation d'études et $d^{\prime \prime}$ orientation professionnelle (Arbeitsamt-Berufsberatung, PMS-centra, AOB).

Ces organisations ont surtout besoin d'informations au service de leurs tâches d'orientation, de conseil et de suivi dans le choix d'une formation professionnelle. On 
a notamment besoin d'informations sur les formations demandées par les pays limitrophes. En général, on accorde encore peu d'importance à ce critère. On peut s'attendre à un besoin croissant d'informations reliè à l'internationalisation des marchés de l'emploi. Les informations souhaitées dans le cadre de l'internationalisation concernent principalement, surtout pour les niveaux moyens ou moins élevés, les possibilités d'emploi dans les pays limitrophes et donc ici au sein de l'Eurégion.

3. Organisations intermédiaires sur le terrain socio-économique, notamment les diverses chambres des métiers, chambres du commerce et de l'industrie, les organisations sectorielles et de branches et les organisations de reconversion et de developpement (p. ex. GOM, LIOF).

Pour ces organisations la collaboration transfrontalière et la formulation d'une politique économique structurelle font ressentir le besoin d'être informées sur le marché de l'emploi eurégional. Le Plan d'ensemble Eurégional peut aider ces organisations dans leurs efforts s'attachant à favoriser le développement économique et la situation de l'emploi. Plus leurs fonctions deviennent transfrontalières, par exemple l'ouverture d'un terrain d'industrie à cheval sur deux pays, plus le besoin d'information est pressant.

4. Organismes d'enseignement, responsables de l'enseignement, surtout en ce qui concerne l'enseignement initial professionnel et la formation professionnelle.

Les organismes d'enseignement travaillant dans une perspective transfrontalière peuvent utiliser les donnèes eurégionales pour l'organisation des formations, des cours et pour l'élaboration des programmes (reconnaissance mutuelle des diplômes, stages hors des frontières, etc). Ceci a déjà été réalisé sur une petite échelle mais il est probable qu'une information systématique pourrait mettre en évidence plus de possibilités transfrontalières et que, vice versa, plus on entreprendra d'actions sur ce terrain, plus le besoin en information croîtra.

\section{Employeurs, autant les entreprises privées que les services publiques.}

Les offres d'emploi difficilement satisfaites requièrent une information complète sur les possibilités de recrutement en dehors des frontières. Ce besoin sera surtout présent dans les entreprises employant des migrateurs pendulaires. Selon toute probabilité ce besoin d'informations se fera de plus en plus sentir au fur et à mesure que le nombre d'employeurs mis au courant, par le Plan d'ensemble Eurégional, des possibilités transfrontalières augmentera. Le Plan d'ensemble Eurégional peut aussi encourager l'implantation de grandes entreprises (internationales) qui, par le fait de leur taille doivent s'adresser au marché du travail international/eurégional. 
6. Administrations régionales et locales: municipalités, Kreise, arrondissements, provinces et encore les organes nationaux dans le cadre de leur politique concernant les parties du pays appartenant à l'Eurégion.

Pour ces organisations une information eurégionale jouera un rôle d'aide à la mise en place de la politique économique et de la politique en matière de marché d'emploi. On pourra, de plus, en examiner les effets à la lumière d'informations comparatives. Plus l'aspect eurégional s'affirme comme, par exemple, par suite de mesures portant sur l'infrastructure, d'établissement de terrains d'entreprises, d'encouragement à l'implantation d'entreprises internationales, plus le besoin d'informations croît.

\section{Fonction auprès du public.}

Internationalisation, Eurégion, migration pendulaire transfrontalière, ces sujets apparaissent régulièrement dans les médias. Ces évolutions ont de plus en plus de répercussions dans la vie quotidienne, surtout dans les régions frontalières. Le public se sent de plus en plus concerné et ceci entraine une demande grandissante d'informations de la part des organes de presse, des autres médias, des services de relations publiques et de la part de particuliers. II est très important de pouvoir avoir accès à une information structurée de base et de connaitre l'adresse où l'on peut se procurer ces informations. La connaissance et la reconnaissance de l'Eurégion par le public repose, également, sur une bonne information.

\section{Elaboration du Plan d'ensemble eurégional}

Indicateurs

Le Plan eurégional Enseignement-Marché du travail a reçu la forme d'un système d'indicateurs. Par indicateur, il faut entendre une donnée simple ou complexe éclairant un certain aspect du marché de l'emploi et de la coordination de l'enseignement avec le marché du travail. Tout indicateur a une fonction propre, explicite, évidente grâce à sa place dans la structure du Plan, sa forme et sa dénomination. On trouve également des indicateurs apportant l'information sur le contexte nécéssaire à la juste interprétation des autres indicateurs. Les indicateurs sont assemblés en tableaux, éventuellement en représentations graphiques et descriptions qualitatives, toujours de la même façon ("signalements"). Pour certains indicateurs, on a ajouté des commentaires plus détaillés et/ou des interprétations.

\section{Groupement des données; comparabilité et exhaustivité}

Dans le Plan d'ensemble Eurégional toutes les données sont présentées par partie eurégionale. Les parties composantes de l'Eurégio sont le Limbourg du sud (néerlandais), la province du Limbourg (B), la province de Liège, la Deutschsprachige 
Gemeinschaft Belgien et la Région Aix-la-Chapelle. Certaines données relatives aux villes plus importantes de l'Eurégio sont également fournies.

Notez que les données relative à la province de Liège incluent fréquemment celle de la 'Deutschsprachige Gemeinschaft', étant donné son appartenance à la Province de Liège; Dans la plupart des publications statistiques cette région ne peut pas être désaggregée plus finement.

Etant donné les objectifs utilitaires du Plan (apporter l'information nécessaire à la définition de la politique et aux processus de travail concrets des institutions de l'Eurégio) on donnera la priorité aux données les plus actuelles sur la situation du marché du travail et ses développements dans chaque composante de l'Eurégio. On attachera moins d'importance à une entière comparabilité des données. Les objectifs utilitaires mentionnés ci-dessus impliquent que le schéma n'est pas, en premier lieu, un instrument de comparaison entre les parties composantes de l'Eurégio; une bonne intelligence de la situation dans les différentes parties de l'Eurégio prime. Pour les éléments (concernant une ou plusieurs parties composantes de l'Eurégio) au sujet desquels on ne dispose pas de chiffres comparables, on présentera les chiffres les plus appropiés. Cela vaut également pour les années auxquelles se rapportent les données: on utilisera, autant que possible, les chiffres les plus récents même si l'année n'est pas la même pour les composantes de l'Eurégio. Selon ce principe, les données absentes pour une des parties de l'Eurégio seront quand même communiquées pour les autres.

Structure et détail

Les possibilités d'utilisation susnommées demande, en général, une information détaillée. Trop de détails peuvent cependant gêner la lisibilité. On veillera donc à la clarté et à l'efficacité du Plan d'ensemble Eurégional de deux manières. Premièrement, la structure du Plan d'ensemble Eurégional, la dénomination et la définition des indicateurs à l'intérieur de cette structure devront toujours éclairer la fonction de l'information. Une structure plus claire permet une sélection ponctuelle de l'information pour certains objectifs pratiques. Deuxièmement, dans les cas appropriés, on présentera des chiffres récapitulatifs et des graphiques à côté de tableaux plus détaillés.

Justification méthodologique

Les données sont rassemblées et traitées, par composante eurégionale, par les membres du groupe d'initiative (voir l'introduction). II s'ensuit donc que la méthode de travail et les sources d'information peuvent différer selon les parties composantes de l'Eurégio. Le Plan renferme aussi bien des données rassemblées par les instituts concernés eux-mêmes que des données provenant des instituts nationaux des pays 
en question. La source sera chaque fois mentionnée par indicateur. Dans toutes ou quasiment toutes les composantes de l'Eurégio on utilise les différentes sources de données suivantes:

* les statistiques démographiques basées sur l'enregistrement de la population et/ou les recensements;

* les statistiques de la population active basées sur des enquêtes et/ou des recensements;

* les données sur la population active des organes exécutifs de la sécurité sociale;

* les données enregistrées sur les demandeurs d'emploi et les offres d'emploi des organismes du service de l'emploi;

* les données sur le développement macro-économique, entre autres les comptes nationaux;

* les statistiques de l'enseignement, en particulier celles des diplômés par type d'enseignement; complétées, pour le Limbourg du sud, par l'enquête, parmi ceux qui ont quitté l'école, sur la destination des diplômés.

Pour la définition des unités les plus importantes dans les indicateurs voir annexe 1.

\section{Structure du plan}

Le texte ci-dessous présente une définition sommaire des indicateurs composant le Plan. Ces définitions et la structure du Plan doivent faire apparaître quelle information peut être retirée des différents indicateurs.

\section{groupe d'indicateurs 1: la population}

Ces indicateurs concernent la population, dans son entier, des différentes composantes de l'Eurégio: volume de la population et sa répartition par âge, part des autres nationalités et densité de population. On étudie, ensuite, spécifiquement, les activités de la population: la participation au travail, ou à d'autres activités (par ex. les études) et pour les actifs, les types d'activités et le background éducatif. Ceci pour trois catégories: la population des 15 - 64 ans (c'est à dire le groupe susceptible d'être actif professionnellement), les jeunes (15 - 24) et les seniors (55 - 64). Les limites des groupes d'âge peuvent varier quelque peu selon les composantes de l'Eurégio.

\section{A population totale}

1.A.1 répartition par âge: (si possible série chronologique).

1.A.2 part des autres nationalités dans la population.

1.A.3 population des villes plus importantes, part des autres nationalités 
1.A.4 densité de population par commune.

1.A.5 developpement de la population 1990-1995

1.B population des $15-64$ ans (population active potentielle)

1.B.1 indice de participation: actif, chômeur, inactif.

1.B.2 types d'emploi: actifs: employé, travail souple, travailleur indépendant, autre.

1.B.3 travail à temps complet ou partiel.

1.C population des $15-24$ ans (les jeunes)

1.C.1 indice de participation.

1.C.2 types d'emploi.

1.C.3 travail à temps complet ou partiel.

1.D population des 55-64 ans (les seniors)

1.D.1 indice de participation.

1.D.2 types d'emploi.

1.D.3 travail à temps complet ou partiel.

groupe d'indicateurs 2: variables du contexte macro-economique

II s'agit ici des indicateurs donnant une image du fonctionnement économique des différentes composantes de l'Eurégio.

2.1 produit régional brut.

2.2 indices conjoncturels en totalité et par secteur.

2.3 taux d'investissement en totalité et par secteur.

2.4 indices de productivité en totalité et par secteur.

groupe d'indicateurs 3: population active

On aborde ici l'analyse de la population active, donc, aussi bien la part profession-

$x x v i$ 
nellement active (population laborieuse) que la part à la recherche d'un emploi. Pour la population laborieuse, on s'intéresse à la nature des activités par secteur ou (plus précisément) par branche industrielle et par catégorie professionnelle, ainsi qu'au background éducatif.

3.1 population laborieuse selon la branche industrielle.

3.2 population laborieuse selon la catégorie professionnelle.

3.3 population laborieuse selon le type d'enseignement le plus suivi.

3.4 chômeurs selon la catégorie professionnelle.

3.5 chômeurs selon le type d'enseignement le plus suivi.

3.6 pourcentage de chômeurs dans les villes plus importantes.

3.7 population laborieuse par secteur selon les types d'emploi.

\section{groupe d'indicateurs 4: marche du travail}

Ce groupe d'indicateurs concerne les rapports de l'offre et de la demande sur le marché de l'emploi, les disparités sur le marché de l'emploi et le placement; là où cela est possible, les prévisions relatives au marché de l'emploi sont reprises.

4.1 rapports actuels de l'offre et de la demande: offres d'emploi/demandeurs d'emploi.

4.2 offres d'emploi satisfaites: résultats des placements par secteur et branche industrielle.

4.3 offres d'emploi satisfaites: résultats des placemente par catégorie professionnelle.

4.4 prévisions de l'accroissement de la demande par profession.

\section{groupe d'indicateurs 5: coordination enseignement - marche du travail}

Ce groupe d'indicateurs traite de la transition entre l'enseignement et le marché du travail. On y étudie le "output" (sortie) de l'enseignement initial, c'est à dire les types d'enseignement ayant une coordination avec le marché de l'emploi (parallèles ou non à une préparation à des études ultérieures). Là où cela est possible, des données sur la transition vers le marché du travail et sur la coordination qualitative avec le marché du travail sont présentées. 
5.1 nombre des diplômés de l'enseignement; éventuellement, fichier de la dernière année de l'enseignement.

5.2 destination du flux de l'enseignement selon le type d'enseignement.

5.3 coordination qualitative entre l'enseignement et la profession selon le type d'enseignement.

xxviii 


\section{Einleitung}

\section{Ziele der Euregionalen Übersicht}

Vor dem Hintergrund demographischer Entwicklungen einerseits und der makrowirtschaftlichen Entwicklung andererseits will die Euregionale Übersicht eine bessere Informierung über den Arbeitsmarkt in der Euregio im allgemeinen und den Anschlu $\beta$ von der Ausbildung an den Arbeitsmarkt im besonderen erreichen. Zu diesem Zweck wurden pro Euregiogebiet übereinstimmende Informationen in einer leicht zugänglichen Form gesammelt.

Das Ziel dieser Euregionalen Übersicht ist vor allem die Unterstützung der Unternehmenspolitik und Arbeitsprozesse von Institutionen und Unternehmen in der Euregio, um damit zur wirtschaftlichen und sozialen Entwicklung der Euregiogebiete und der Euregio als Ganzes beizutragen. Es wird u.a. aufgrund der Pilotstudie erwartet, daß vor allem die folgenden Arten von Institutionen und Unternehmen davon profitieren können:

1. Organisationen auf dem Gebiet der Arbeitsvermittlung, sowohl öffentliche (Arbeitsamt, VDAB/FOREM, RBA) wie private (z.B. Zeitarbeitbüros).

Die Euregionale Übersicht will für diese Zielgruppe vor allem dem Bedarf an mehr allgemeinen Informationen über die euregionalen Entwicklungen in Hinblick auf die strategische Beschlußfassung auf politischer Ebene (Politik der jeweiligen Institutionen bezüglich der Internationalisierung) und über die Auswertung dieser Politik, Informationen über Arbeitsmarktprobleme zugunsten der Schulungspolitik und Informationen über grenzüberschreitende Möglichkeiten zugunsten der Vermittlungspolitik entsprechen.

Was die Schulungs- und Vermittlungspolitik betrifft, hat die Euregionale Übersicht vor allem eine Wahrnehmungsfunktion; sie bietet Möglichkeiten für grenzüberschreitende Schulungsprojekte und informiert darüber, wo grenzüberschreitende Möglichkeiten der Stellenvermittlung usw. erwartet werden. Die Euregionale Übersicht fungiert hier neben dem bereits bestehenden Informationsfluß zwischen den Arbeitsverwaltungen, wobei es sich hier hauptsächlich um den Austausch von freien Stellen handelt. Die Euregionale Übersicht ergänzt diese dort, wo es um allgemeine Informationen, Hintergrundinformationen und - falls technisch möglich - die Erwartungen für die nahe Zukunft geht. Es ist anzunehmen, daß der Bedarf nach systematisierten Informationen in dem Maße größer wird wie das relative Interesse der grenzüberschreitenden Aktivitäten zunimmt. 
2. Organisationen auf dem Gebiet der Studien- und Berufsberatung, sowohl öffentliche (Arbeitsamt-Berufsberatung, PMS-Zentren, AOB) wie private.

Diese Zielgruppe hat hauptsächlich Bedarf an Informationen im Interesse der Informierung, Beratung und Begleitung bei der Wahl berufsbezogener Ausbildungen. Es handelt sich hier vor allem um Informationen über Ausbildungen, wonach auch oder gerade im benachbarten Ausland Bedarf besteht. Im allgemeinen wird dieses Kriterium noch zu wenig berücksichtigt. Vermutlich nimmt hier der Informationsbedarf in Zusammenhang mit der Internationalisierung der Arbeitsmärkte zu; vor allem auf dem niedrigeren und mittleren Niveau handelt es sich bei dieser Internationalisierung in erster Linie um Informationen über Arbeitsmöglichkeiten im nahegelegenen Ausland, also in diesem Falle innerhalb der Euregio.

3. Zwischeninstanzen auf sozialwirtschaftlichem Gebiet, hauptsächlich die diversen Handwerks-, Industrie- und Handelskammem, Branchen- und Sektororganisationen und regionalen Umstellungs-/Umorganisations- und Entwicklungsgesellschaften (z.B. GOM, LIOF).

Bei diesen Zwischeninstanzen erwächst der Bedarf an euregionaler Arbeitsmarktinformation aus der grenzüberschreitenden Zusammenarbeit und der Formulierung der wirtschaftlichen Strukturpolitik. Die Euregionale Übersicht könnte die Aufgabenstellung dieser Organisationen auf dem Gebiet der Förderung der wirtschaftlichen Entwicklung und der Beschäftigung unterstützen. In dem Maße wie der euregionale Aspekt dieser Aufgabenstellung an Wichtigkeit zunimmt (z.B. durch die Eröffnung von grenzüberschreitenden Betriebsgeländen und Unternehmen), nimmt auch der Informationsbedarf zu.

4. Ausbildungs- und Lehranstalten, Ausbildungsbehörden, vor allem auf dem Gebiet der anfänglichen Berufsausbildung und spezifische fachbezogene Schulung.

Der Bedarf an euregionaler Information bei Ausbildungs- und Lehranstalten usw. bezieht sich auf die Planung von Ausbildungen und Kursen in Hinblick auf die grenzüberschreitenden Möglichkeiten und das Erstellen von Ausbildungsinhalten zugunsten dieser Möglichkeiten (Doppeldiplom für grenzüberschreitendes Praktikum und dergleichen). Man hat hier in bescheidenem Maß bereits Erfahrungen gesammelt. Es wird erwartet, daß systematische Informationen auf mehr Möglichkeiten hinweisen werden und daß andererseits eine zunehmende Aktivität auf diesem Gebiet zu einem größeren Bedarf an Informationen führen wird.

\section{Arbeitgeber, sowohl Privatunternehmen wie Behörden und öffentliche Dienste.}

Ein offensichtlicher Informationsbedarf ist hier die Erforschung von Möglichkeiten zur Werbung über die Grenze bei schwierig zu besetzenden freien Stellen. Dieser 
Bedarf wird vor allem bei Unternehmen liegen, die bereits heutzutage von Pendlern Gebrauch machen. Wahrscheinlich wird dieser Informationsbedarf zunehmen, wenn mehr Arbeitgeber durch die Euregionale Übersicht auf Möglichkeiten der grenzüberschreitenden Werbung hingewiesen werden. Die Euregionale Übersicht kann auch die Niederlassung von großen (internationalen) Unternehmen unterstützen, die durch ihren Umfang auf den internationalen/euregionalen Arbeitsmarkt angewiesen sind.

6. Örtliche und regionale Behörden: Gemeinden, Kreise, Arrondissements, Provinzen; ferner Landesbehörden insoweit es um die Politik bezüglich der Landesteile in der Euregio geht.

Für die verschiedenen Behörden wird die euregionale Information vor allem bei der Unterstützung der wirtschaftlichen Struktur- und Arbeitsmarktpolitik eine Rolle spielen können. Auch bei der Auswertung dieser Politik können vergleichende Informationen wichtig sein. In dem Maße wie der euregionale Aspekt dieser Politik immer wichtiger wird, z.B. bei grenzüberschreitenden infrastrukturellen Maßnahmen, der Gründung von Betriebsgeländen, das Einholen von internationalen Unternehmensgründungen und dergleichen, nimmt die Wichtigkeit dieser Informationen zu.

\section{Die öffentliche Funktion}

Internationalisierung, die Euregio, Pendelverkehr und Grenzarbeit: diese Themen kommen regelmäßig an die Öffentlichkeit. Der wachsende Einfluß dieser Entwicklungen auf das tägliche Leben läßt auch das Interesse bei den Bürgern, insbesondere in den Grenzregionen, zunehmen. Dies führt zu einer Nachfrage nach Informationen bei der Presse, bei sonstigen Medien, Informationsdiensten und Privatpersonen. Dieser Informationsbedarf ist abhängig von den aktuellen Themen und deshalb auch sehr unterschiedlich. Die stetige Verfügbarkeit systematischer Grundlageninformationen und eine erkennbare "Adresse", wo diese zu bekommen sind, sind dann auch von Wichtigkeit. Auch für die öffentliche Bekanntheit und Akzeptanz der Euregio-Entwicklung ist die Verfügbarkeit von guten Informationen wichtig.

\section{Gestaltung der Euregionalen Übersicht}

\section{Indikatoren}

Die Euregionale Übersicht über Ausbildung und Arbeitsmarkt hat die Form eines Indikatorensystems erhalten. 'Indikatoren' sind in diesem Fall einfache oder zusammengefaßte Daten, die einen bestimmten Aspekt des Arbeitsmarktes oder den Anschluß von der Ausbildung an den Arbeitsmarkt beinhalten. Jeder Indikator hat eine klare selbständige Funktion, die durch den Platz innerhalb der Struktur der Übersicht sowie durch Formgebung und Bezeichnung deutlich ist. Daneben gibt es 
Indikatoren, die die Funktion von Hintergrundinformation haben, die für die korrekte Interpretation von anderen Indikatoren erforderlich ist. Die Indikatoren sind nach einem festen Muster ('Merkmale') anhand von Tabellen, eventuell Grafiken sowie qualitativen Beschreibungen dargestellt. Bei einigen Indikatoren sind nähere Erläuterungen und/oder Interpretationen hinzugefügt worden.

\section{Zusammenstellung von Daten, Vergleichbarkeit und Vollständigkeit}

In der Euregionalen Übersicht werden alle Daten für jedes Euregiogebiet separat präsentiert. Bei diesen Euregiogebieten handelt es sich um das niederländische Südlimburg, die belgischen Provinzen Limburg und Lüttich, die deutschsprachige Gemeinschaft Belgien und die Regio Aachen. Außerdem werden einige Daten über die größeren Städte der Euregio präsentiert.

In den Daten für die Province de Liège wird oft auch die Deutschsprachige Gemeinschaft mitgezählt, weil sie Teil des Province de Liège ist. Diese Region kann in den statistischen Daten meistens nicht weiter aufgeteilt werden.

In Anbetracht des Verwendungszweckes (Verschaffen von Informationen zugunsten der Unternehmenspolitik und der konkreten Arbeitsprozesse von Institutionen innerhalb der Euregio) hat eine möglichst vollständige und aktuelle Übersicht über die Arbeitsmarktsituation und -entwicklungen eines jeden Euregiogebietes eine höhe Priorität erhalten. Die komplette Vergleichbarkeit der Daten steht fürs erste noch an zweiter Stelle. Die obengenannten Verwendungszwecke implizieren, daß die Euregionale Übersicht nicht in erster Linie für einen Vergleich zwischen den Euregiogebieten verwendet wird, sondern daß eine gute Übersicht über die Situation in jedem einzelnen Euregiogebiet an erster Stelle steht.

Abschnitte, bei denen (für ein oder mehrere Euregiogebiete) keine vergleichbaren Zahlen vorliegen, werden mit möglichst zutreffenden Zahlen versehen. Gleiches gilt für die Jahreszahlen, auf die sich die Daten beziehen: Es werden soweit wie möglich die aktuellsten Zahlen eingesetzt, auch wenn diese für jedes Euregiogebiet unterschiedlich sind. Aus dem gleichen Grunde werden Daten, die bei einem bestimmten Euregiogebiet fehlen, bei einem anderen dennoch eingesetzt.

\section{Struktur und Detail}

Die genannten Verwendungszwecke erfordern im allgemeinen eine detaillierte Information. Zuviele Details gehen jedoch auf Kosten der Übersichtlichkeit. Daher wurde die Übersichtlichkeit und Brauchbarkeit der Übersicht auf zwei Weisen überwacht. Erstens verdeutlichen die Struktur der Euregionalen Übersicht und die Bezeichnung sowie die Umschreibung der Indikatoren innerhalb dieser Struktur stets die Funktion der Information. Diese Struktur ermöglicht zudem die gezielte Auswahl 
von Informationen für bestimmte Verwendungszwecke. Zweitens werden dort, wo das relevant ist, zusammenfassende Zahlen und Grafiken neben den etwas detaillierteren Tabellen dargestellt.

\section{Methodologische Verantwortung}

Die Daten wurden pro Euregiogebiet gesammelt und von den Mitgliedern der Initiativgruppe (siehe Vorwort) bearbeitet. Dies impliziert, daß die Arbeitsweise und die genutzten Informationsquellen bei jedem Euregiogebiet unterschiedlich sein können. Die Euregionale Übersicht umfaßt sowohl Daten, die von den betreffenden Institutionen selbst gesammelt wurden wie auch Daten von nationalen Einrichtungen innerhalb der betreffenden Länder. Pro Indikator wird jeweils die Quelle genannt.

In allen oder nahezu allen Euregiogebieten wurden die nachstehenden Arten von Datenquellen verwendet:

* demographische Statistiken auf der Grundlage des Einwohnermeldeamtes und/oder Volkszählungen;

* Statistik der Berufsbevölkerung, auf der Grundlage von Erhebungen und/oder Volkszählungen;

* Daten über die Berufsbevölkerung der Ausführungsorgane der sozialen Sicherheit;

* Erfassung von Daten über Arbeitssuchende und offenen Stellen der Arbeitsverwaltungen;

* verschiedene Datenquellen über makrowirtschaftliche Entwicklungen, u.a. nationale Rechnungen;

* Ausbildungsstatistiken, hauptsächlich über diplomierte Personen pro Ausbildungstypus; für Südlimburg ergänzt um eine Untersuchung in bezug auf Schulabgänger und der Bestimmung von diplomierten Personen.

Die Definitionen der wichtigsten Einheiten innerhalb der Indikatoren sind der Anlage 1 zu entnehmen.

\section{Struktur des Übersichts}

Hierunter werden die Indikatoren, aus den das Übersicht zusammengestellt ist, kurzgefaßt umschrieben. Aus diesen Umschreibungen und aus dem Struktur des übersicht zeigt sich welche Information an den unterschiedenen Indikatoren entnommen werden kann.

\section{Indikatorengruppe 1: die Bevölkerung}

Diese Indikatoren betreffen die Bevölkerung insgesamt der unterschiedenen Teile der Euregio. Einige Hintergrundinformation wird präsentiert: Umfang und Altersaufbau der Bevölkerung, Anteil anderer Nationalitäten und Bevölkerungsdichte. Darauf 
wird eingegangen auf die Typen Tätigkeit der Bevölkerung: die teilnehmung an Arbeit und anderen Tätigkeiten (a.B. Studie) und von den Arbeitstätigen die Typen Beschäftigung und den Ausbildungshintergrunf. Dies wird gemacht für drie Kategorien: die Bevölkerung von 15 - 64 Jahr (also die Gruppe die Berufstätig sein kann), die Jugend (15 - 24) und die Senioren (55 - 64 Jahr). Die grenzen dieser Altersklassen können pro Eurtegioteil unterschieden sein.

\section{A Bevölkerung, generell}

1.A.1 Bevölkerung insgesamt, Altersaufbau (indem möglich Zeitspanne).

1.A.2 Anteil anderer Nationalitäten in der Bevölkerung.

1.A.3 Bevölkerung größere Städte, Anteil anderer Nationalitäten.

1.A.4 Bevölkeringsdichte pro Gemeinde.

1.A.5 Entwicklung der Bevölkerung 1990-1995

\section{B Bevölkerung, Altersklasse 15 - 64 Jahre (potentielle Berufsbevölkerung)}

1.B.1 Teilnehmerindex: beschäftigt, arbeitslos, nicht aktiv.

1.B.2 Beschäftigungstypen: Beschäftigte nach Arbeitnehmern, Selbständigen oder übrigen.

1.B.3 Vollzeit- und Teilzeitarbeit.

1.C. Bevölkerung, Altersklasse 15 - 24 Jahre (Jugendliche)

1.C.1 Teilnehmerindex.

1.C.2 Beschäftigungstypen.

1.C.3 Vollzeit- und Teilzetarbeit.

\section{D Bevölkerung, Altersklasse 55 - 64 Jahre (Senioren)}

1.D.1 Teilnehmerindex.

1.D.2 Beschäftigungstypen.

1.D.3 Vollzeit- und Teilzeitarbeit.

xxxiv 
Indikatorengruppe 2: Makroökonomische Hintergrundvariablen

Hier geht es um Indikatoren die ein Bild geben des ökonomische Funktionieren der unterschiedenen Teile der Euregio.

\subsection{Regionales Bruttosozialprodukt.}

2.2 Konjunkturindizien: insgesamt und nach jeweiligen Sektoren.

2.3 Investitionsquote pro Sektor.

2.4 Produktivitätsindizien nach Sektor und insgesamt.

\section{Indikatorengruppe 3: Berufsbevölkerung}

Hier wird verbreitet über der Berufsbevölkerung, also über diesen Teil der Bevölkerung das erwerbstätig ist oder arbeitsuchend ist. Von der erwerbstätigen Bevölkerung werden die Art der Beschätigung pro Sektor oder (mehr detailliert) pro Erwerbszweig und pro Berufsgruppe nach Ausbildungshintergrund erleuchtert.

\subsection{Erwerbstätige Bevölkerung nach Erwerbszweig.}

3.2 Erwerbstätige Bevölkerung nach Berufsgruppe.

3.3 Erwerbstätige Bevölkerung nach höchstem Ausbildungsniveau.

3.4 Arbeitslose nach Berufsgruppe.

3.5 Arbeitslose nach höchstem Ausbildungsniveau.

3.6 Prozentsatz Arbeitslose in großen Städten und ggf. in den Subregionen.

3.7 Beschäftigte pro Sektor nach Art der Beschäftigung.

\section{Indikatorengruppe 4: Arbeitsmarkt}

Diese Indikorengruppe betrifft die Verhältnisse zwischen Nachfrage und Angebot auf dem Arbeitsmarkt und die Probleme auf dem Arbeitsmarkt und bei der Arbeitsvermittlung. Indem möglich werden Prognosen des Arbeitsmarktes aufgenommen.

4.1 Aktuelle Verhältnisse zwischen Nachfrage und Angebot: Offene Stellen gegenüber Arbeitssuchenden.

4.2 Besetzung von offenen Stellen: Vermittlungsergebnisse pro Sektor und Erwerbszweige 
4.3 Besetzung von offenen Stellen: Vermittlungsergebnisse pro Berufsgruppe.

\subsection{Nachfrageprognosen.}

Indikatorengruppe 5: Anschluß von der Ausbildung an den Arbeitsmarkt Diese Gruppe Indikatoren betrifft den Uebergang vom Unterichtsystem nach dem Arbeitsmarkt. Der Austritt aus den Anfangsschultypen mit Anschluß an dem Arbeitsmarkt (auch aus dem dualen System) wird dargestellt. Indem möglich werden Daten über dem Übergang nach dem Arbeitsmarkt und dem qualitativen Anschluß an dem Arbeitsmarkt präsentiert.

5.1 Anzahl Abiturienten der Schultypen

5.2 Bestimmung des Austritts aus den Schultypen.

5.3 Qualitativer Anschluß von Ausbildung an den Beruf nach Ausbildungstyp. 